\title{
Role of m6A in osteoporosis, arthritis and osteosarcoma (Review)
}

\author{
YIBO HU and XIAOHUI ZHAO
}

\author{
Department of Orthopaedic Trauma, The Affiliated Hospital of Qinghai University, Xining, Qinghai 810000, P.R. China
}

Received August 5, 2020; Accepted March 11, 2021

DOI: $10.3892 / \mathrm{etm} .2021 .10358$

\begin{abstract}
RNA modification is a type of post-transcriptional modification that regulates important cellular pathways, such as the processing and metabolism of RNA. The most abundant form of methylation modification is RNA N6-methyladenine (m6A), which plays various post-transcriptional regulatory roles in cellular biological functions, including cell differentiation, embryonic development and disease occurrence. Bones play a pivotal role in the skeletal system as they support and protect muscles and other organs, facilitate movement and ensure haematopoiesis. The development and remodelling of bones require a delicate and accurate regulation of gene expression by epigenetic mechanisms that involve modifications of histone, DNA and RNA. The present review discusses the enzymes and proteins involved in mRNA m6A methylation modification and summarises current research progress and the mechanisms of mRNA m6A methylation in common orthopaedic diseases, including osteoporosis, arthritis and osteosarcoma.
\end{abstract}

\section{Contents}

1. Introduction

2. Enzymes and proteins involved in modification by $\mathrm{m} 6 \mathrm{~A}$

3. m6A and osteoporosis

4. m6A and arthritis

5. m6A and osteosarcoma

6. Future prospects

\section{Introduction}

The central dogma is one of the most important basic laws in modern biology that reveals the process by which genetic information is conveyed from DNA to RNA through transcription, and subsequently to protein through translation (1).

Correspondence to: Dr Xiaohui Zhao, Department of Orthopaedic Trauma, The Affiliated Hospital of Qinghai University, 29 Tong-Ren Road, Xining, Qinghai 810000, P.R. China

E-mail: 18229016281@163.com

Key words: N6-methyladenine, methyltransferase, demethylase, reader proteins, common orthopaedic diseases
Recent advancements in genetic technologies have revealed that genetic information encoded in the genome is not only an alignment of base sequences but is also associated with other multifarious levels of regulation, such as DNA methylation and histone modification (2). The discovery of these epigenetic research results has driven the central dogma. Increasing evidence suggest that RNA plays a vital role in the central dogma (3). Genetic material is regulated at various levels, in addition to DNA and RNA levels (4). RNA modification is a type of post-transcriptional modification that controls important pathways, such as RNA processing and metabolism (5). With the advancements in sequencing technology, the dynamics of RNA modification and its biological functions have received considerable attention from scientists and have become new research hotspots in the field of epigenetics (6-9).

RNA methylation has been extensively identified in vertebrates, plants, yeasts, bacteria, archaea and viruses (10), and N6-methyladenine (m6A) is the most common form of RNA methylation (11). Generally, m6A modifications occur at the conserved RRACH motif $(\mathrm{R}=\mathrm{G}$ or $\mathrm{A} ; \mathrm{H}=\mathrm{A}, \mathrm{C}$ or $\mathrm{U})$ and are concentrated near the stop codons of mRNAs (12) (Fig. 1). Notably, with the development of enzymatic technology, m6A modification enzymes have been identified, among which, methyltransferase-like (METTL)3, METTL14 and Wilms' tumor 1-associating protein (WTAP) complexes are the main m6A methyltransferases (13-15), whereas fat-mass and obesity-associated protein (FTO) and $\alpha$-ketoglutarate-dependent dioxygenase alkB homologue 5 (ALKBH5) are demethylases (16,17) (Fig. 1). Currently, m6A is the most studied RNA modification (18). m6A modification plays various post-transcriptional regulatory roles, including transcription regulation, selective splicing, stabilization and translation of RNA, by binding proteins that contain the YTH domain (19) (Fig. 1). In addition, m6a modifications regulate cellular biological functions involved in cell differentiation, embryonic development and disease occurrence (20).

The discovery of m6A methyltransferases and demethylases proved that RNA modification is dynamic and reversible, and promoted the study of RNA modifications from micro-regulation mechanisms to epitranscriptome levels (21). However, other modification forms, including 5-methylcytosine (22) and 1-methyladenine (23) are currently at initial stages, and their modification enzymes, dynamic regulation and biological functions require further studies and development.

The main function of bones is to provide support and protection (24-26). However, bones also have other important 
functions, including facilitation of movement, haematopoiesis and formation of reservoirs of minerals, such as calcium $(27,28)$. The development and remodelling of bones require an accurate regulation of gene expression in bone cells, a process that is affected by epigenetic mechanisms, such as histone modification, DNA methylation and RNA methylation $(29,30)$. Previous studies have reported that the disruption of epigenetic processes in bone cells can notably influence the function and activity, and contribute to the pathogenesis of bone-associated diseases (31-34). The present review summarizes the latest research concerning $\mathrm{m} 6 \mathrm{~A}$ and discusses the newly identified roles that m6A plays in common orthopaedic diseases.

\section{Enzymes and proteins involved in modification by m6A}

\section{Writers}

METTL3. Increasing evidence suggest that modification by m6A is mediated by methyltransferase complexes that are composed of several proteins (35). METTL3 was the first m6A methyltransferase that was identified (36). Methyltransferase MT-A70 was identified as part of a large protein complex that was isolated from enzymatic mammalian cell nuclear extracts (37), and is the leading catalytic enzyme of the m6A system (9,38). METTL3 contains two Cys-Cys-Cys-His $(\mathrm{CCCH})$-type zinc finger motifs at the $\mathrm{N}$-terminus and one catalytic motif $[\mathrm{D} / \mathrm{N} / \mathrm{S} / \mathrm{H}] \mathrm{PP}(\mathrm{Y} / \mathrm{F} / \mathrm{W})]$ in the methyltransferase domain $(39,40)$. It has functions in all the stages of the RNA lifecycle, including pre-mRNA splicing (41), nuclear export (17), translation regulation (42), mRNA decay (43) and microRNA (miRNA/miR) processing (44). Generally, METTL3 forms a stable heterodimeric complex with METTL14, which is another important methyltransferase of m6A (45), with the help of other components of writers. This methylation was reported to occur at the N6 position of adenosine on mRNA and was speculated to be a co-transcriptional methylation (46). Notably, disruption of METTL3 homologs results in severe developmental defects in yeasts, and METTL3 homologs have lethal phenotypes in Arabidopsis and mice (47-50). Recent evidence suggested that METTL3 is upregulated and plays an oncogenic role involving increased m6A expression levels in different types of cancer, such as bladder cancer (51), lung cancer (52), colorectal cancer (53), glioma (54), breast cancer (55), leukaemia (56) and other cancers including gastric cancer and melanoma $(57,58)$. However, other studies have demonstrated opposing results from the same types of cancer (59-61). The potential molecular mechanisms have been investigated and include the regulation of downstream non-coding RNAs (62), modulation of miRNA processing via DGCR8 (51), regulation of apoptosis (57) and regulation of the PI3K/AKT pathway $(62,63)$.

METTL14. Another core writer is METTL14. Despite having $\sim 22 \%$ sequence identity and an almost identical topological structure with the methyltransferase domains of METTL3, METTL14 is considered a pseudomethyltransferase $(39,45)$. The function of METTL14 in the complex remains unclear. In a surface electrostatic potential analysis, RNA binding affinity and methyltransferase activity were revealed to moderately decrease in the complex with double mutations in K297E and R298E, suggesting that METTL14 may be involved in RNA interaction; however, the binding sites of
S-adenosylmethionine and the DPPW functional domains of METTL14 are responsible for the catalysis of m6A formation (64). METTL14 is a vital member of the m6A methyltransferase complex (65). Notably, several studies have demonstrated that METTL3 and METTL14 are associated with each other $(14,45,66)$. Once METTL3 and METTL14 function individually, they exhibit nearly undetectable methyltransferase activity, whereas the METTL3-METTL14 complex displays methyltransferase activity (14). However, whether METTL14 exhibits methyltransferase activity after binding to additional factors remains unknown. METTL14 is also involved in the regulation of several tumour processes $(67,68)$. For example, the METTL14-m6A-Notch1 pathway plays a critical role in bladder tumorigenesis and bladder tumour-initiating cells (69). In haematopoietic stem cells and liver tumour cells, METTL14 is downregulated and attenuates the tumorigenesis of acute myeloid leukaemia (AML) (70).

WTAP. Another component of the human m6A methyltransferase complex is the WTAP, which plays a critical role in $\mathrm{m} 6 \mathrm{~A}$ formation via a mechanism that differs from the mechanisms observed in METTL3 and METTL14 (71). In a WTAP knockdown study, global m6A levels in human cell lines were reported to be markedly decreased, which indicates its significance in producing a distinct landscape of mRNA methylation (72). WTAP predominantly acts as a regulatory subunit that initially binds to target RNA and subsequently recruits dimers formed by the catalytic subunits, METTL3 and METTL14, to perform catalytic functions owing to a lack of a catalytic domain (71). Furthermore, METTL3 levels were revealed to be important to WTAP protein homoeostasis, whereby METTL3 regulates WTAP expression at various levels via different mechanisms, including mRNA translation and stabilization (73). Taken together, these findings suggest that the components of the methyltransferase complex are essential in the formation of m6A. In addition, WTAP is overexpressed in different types of tumours, including AML (15,74,75), and interacts with different proteins associated with cell proliferation and RNA processing (75). Notably, disruption of WTAP results in embryonic lethality, which is indicative of its vital biological function in the development of vertebrates (76).

Zinc finger CCCH domain-containing protein 13 (ZC3H13). In addition to the core complex of METTL3, METTL14 and WTAP, several other proteins have been implicated in regulating RNA m6A. For example, Virilizer and Hakai were identified as components associated with WTAP in mammalian cells. Endogenous protein complexes from different species in metazoans were studied via quantitative mass spectrometry, and ZC3H13-WTAP-Virilizer-Hakai was identified as an evolutionarily conserved complex (77). ZC3H13 plays a critical role in anchoring WTAP, Virilizer and Hakai in the nucleus to facilitate m6A methylation, and regulates mESC self-renewal (77). ZC3H13 also participates in the development and progression of different types of tumours $(68,78)$. It has been reported that $\mathrm{ZC} 3 \mathrm{H} 13$ expression is substantially downregulated in clear cell renal cell carcinoma tissues (79). Conversely, ZC3H13 expression is substantially upregulated in colon adenocarcinoma tumour tissues compared with adjacent mucosa (80). 


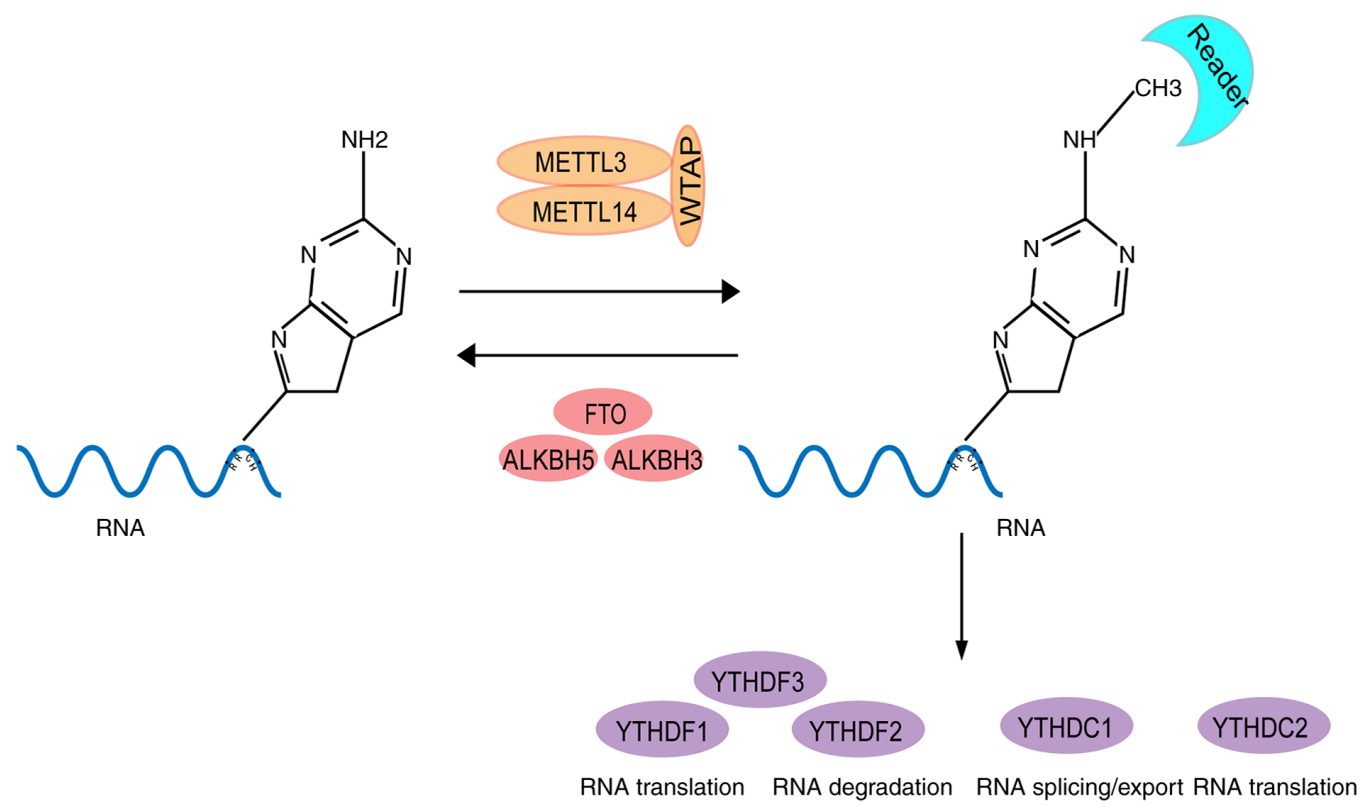

Figure 1. Dynamic regulation of RNA m6A levels by m6A and the known functions of m6A in regulation of RNA metabolism. m6A modification is a dynamic and reversible process. m6A modifications are catalysed by the methyltransferase complex, which consists of METTL3, METTL14 and WTAP (writers) and can be removed by demethylases, FTO and ALKBH5 (erasers). m6A modifications are functionally facilitated by the m6A binding proteins, YTHDF1-3 and YTHDC1-2 (readers), which leads to changes in RNA splicing, RNA stability and RNA nuclear export. m6A, RNA N6-methyladenine; METTL, methyltransferase-like; WTAP, Wilms' tumor 1-associating protein; FTO, fat-mass and obesity-associated protein; ALHBH, $\alpha$-ketoglutarate-dependent dioxygenase alkB homologue; YTHDF, YTH domain family; YTHDC, YTH domain containing.

\section{Erasers}

FTO. FTO, also known as ALKBH9, was identified as the first RNA demethylase in 2011 (81). The discovery of FTO resulted in the identification of $\mathrm{m} 6 \mathrm{~A}$ functions in a reversible and dynamic mode (82). The regulation of body mass and obesity was identified to be the primary function of FTO, as overactivation of FTO was reported to increase food intake and result in obesity, whereas an FTO disorder was reported to cause growth retardation $(83,84)$. Increasing evidence suggest that FTO dysfunction can contribute to the development of cancer. For example, FTO expression is upregulated in breast cancer, which promotes breast cancer cell proliferation (85). FTO expression is also upregulated in hepatocellular carcinoma (HCC) tissues, which is associated with poor patient prognosis (16). Furthermore, FTO has been associated with AML (86), melanoma (87) and lung cancer (88).

ALKBH5. ALKBH5 is another m6A demethylase (89), the function of which remains partly unknown. Both FTO and ALKBH5 belong to the $\alpha$-ketoglutarate-dependent dioxygenase family, which demethylate m6A in an Fe (II)and $\alpha$-ketoglutaric acid-dependent manner $(90,91)$. Several studies have reported that ALKBH5 affects the pathogenesis and development of diseases, such as ALKBH5-deficiency, which results in testis atrophy and reduction in sperm number and motility $(17,92,93)$. ALKBH5 is overexpressed in glioblastoma stem-like cells (GSCs), which maintains GSC tumorigenicity (94), and is involved in the proliferation and metastasis of non-small cell lung cancer (95). In addition, ALKBH5 affects the m6A levels of lncNEAT1, and subsequently promotes enhancer of zeste homolog 2 expression in gastric cancer invasion and metastasis (96).
$A L K B H 3$. Recently, ALKBH3 was identified as another m6A demethylase (97). ALKBH3 has substrate specificity for N6-meA, 1-meA, and 3-meC, and ALKBH3-mediated tRNA demethylation has been reported to increase protein translation efficiency (98). With similar functions as other 'eraser' proteins, ALKBH3 mediates RNA demethylation and subsequently exerts effects on protein synthesis in cancer cells, thereby influencing tumour development and progression (99). However, further studies are required to determine substrate preference of ALKBH3 for different RNA types.

Readers. The reversible and dynamic regulation of m6A modification is mediated by the functional interaction between m6A writers and erasers; however, to identify downstream biological functions, m6A must be recognised by several readers $(46,100)$. Several YTH domain family (YTHDF) members, including YTHDF1, YTHDF2, YTHDF3, YTH domain containing (YTHDC)1 and YTHDC2, have been identified as general 'reader' proteins (43).

YTHDF2. YTHDF2 was identified as the first m6A reader (101). YTHDF2 selectively recognises $\mathrm{m} 6 \mathrm{~A}$ and regulates mRNA degradation through its C-terminal region; more than 3,000 cellular RNA targets of YTHDF2, including mRNAs and non-coding RNAs, were identified (43). The binding sites of YTHDF2 are mainly in the 3'-untranslated region that is rich in GAC sequence, which is consistent with the distribution characteristics of m6A (102). Furthermore, the N-terminal region of YTHDF2 reportedly recruits the CCR4-NOT adenosylase complex, thus accelerating the degradation of substrate RNA (103). YTHDF2 has also been demonstrated to play essential roles in diverse biological processes, such as neural development, cancer progression, maternal mRNA 
clearance, haematopoietic stem cell expansion and male fertility (104-107).

YTHDF1. Unlike YTHDF2, YTHDF1 can bind to m6A sites around the stop codons in mRNAs (108). YTHDF1 specifically binds to m6A-containing mRNAs and accelerates cap-dependent translation by recruiting eIF3, eIF4E, eIF4G, PABP and the 40S ribosomal subunit (108). As a 'reader' protein, YTHDF1 is also involved in several biological processes such as enhances protein synthesis and regulate Pulmonary Hypertension $(42,109)$. A previous study demonstrated that YTHDF1 promotes the translation of mA-methylated neuronal mRNAs, which contributes to learning and memory (110). YTHDF1 also plays a role in the malignant nature of cancer, whereby patients with colorectal cancer and upregulated YTHDF1 expression have a considerably poor prognosis (111). The cell cycle progression and metabolism of HCC are also regulated by YTHDF1 (112).

YTHDF3. YTHDF3 shares $>65 \%$ protein sequence identity with YTHDF1 and YTHDF2 (12). In addition, YTHDF3 can interact with YTHDF1 and YTHDF2 to enhance the binding ability of YTHDF1 or YTHDF2 to RNA-containing m6A modified substrates, and thereby promote translation or degradation (107). YTHDF3 can also interact with several cellular proteins such as PABP1 and eIF4G2 to exert cell-specific regulatory functions (113). A study revealed that YTHDF3 can target YAP and participate in YAP signalling, which facilitates m6A-modified long non-coding RNA (lncRNA) GAS5 degradation, and provides insight on CRC progression (114). Furthermore, YTHDF3 is involved in the viral life cycle as it hampers interferon-dependent antiviral responses by accelerating the translation of $\mathrm{FOXO} 3$, and is considered a regulator of HIV $(113,115)$.

YTHDC1. Unlike YTHDF1, YTHDF2 and YTHDF3, which are located in the cytoplasm, YTHDC1 is located in YT bodies adjacent to nuclear speckles in nucleus (116). YTHDC1 cooperates with nuclear RNA export factor 1 and the three prime repair exonuclease mRNA export complex by interacting with SRSF3 and exports m6A-methylated mRNAs from the nucleus (116). YTHDC1 interacts with metadherin and affects cancer development and progression (117). YTHDC1 also plays essential roles in the development of spermatogonia in males and the growth and maturation of oocytes in females (118).

YTHDC2. YTHDC2, the only RNA helicase-containing and multi-domain $\mathrm{m} 6 \mathrm{~A}$ reader, has been demonstrated to exhibit ATP-dependent RNA helicase activity $(119,120)$. YTHDC2 improves the translation efficiency of target mRNA by interacting with meiosis-specific coiled-coil domain and 5'-3'exoribonuclease 1 after recognising m6A (121). A previous study reported that YTHDC2 affects the expression of drug-metabolizing $\mathrm{P} 450$ isoforms by mediating CYP2C8 mRNA degradation (122). YTHDC2 also plays a conserved role in mouse germ cell fate transition (123). In addition, YTHDC2 contributes to the metastasis of colon tumours and the proliferation of Huh7 HCC cells $(120,124)$.
Other $m 6 A$ readers. In addition to the members of the YTHDF, other proteins that act as $\mathrm{m} 6 \mathrm{~A}$ readers have been identified. The RNA-binding protein, HNRNPA2B1, binds to m6A-modifying RNAs, and its biochemical footprint is consistent with that of the m6A consensus motif (125). HNRNPA2B1 binds to m6A in subsets of primary miRNA transcripts, interacts with the DGCR8 microprocessor complex protein and increases primary miRNA processing (125). In addition, insulin-like growth factor $2 \mathrm{mRNA}$-binding proteins (IGF2BPs), including IGF2BP $1 / 2 / 3$, can recognise $\mathrm{m} 6 \mathrm{~A}$ and improve the stability and translation of mRNAs in an m6A-dependent manner; however, this mechanism requires further investigation (126).

\section{3. m6A and osteoporosis}

METTL3 and osteoporosis. Osteoporosis is the most common bone disorder worldwide, which affects $>200$ million people, and is characterised by decreased bone mineral density (BMD) and increased risk of osteoporotic fracture (127,128). The main pathological changes of osteoporosis are characterised by low bone mass and excessive accumulation of adipose tissue in the bone marrow milieu (129), and bone homoeostasis plays an essential role in the pathogenesis of osteoporosis (11). Bone homoeostasis is mainly maintained by osteoblasts, osteocytes and osteoclasts (130) (Fig. 2A). Osteoblasts produce bone by synthesising extracellular matrix containing various proteins, particularly type I collagen $(131,132)$. The extracellular matrix is deposited as osteoid and is subsequently mineralized through the accumulation of calcium phosphate in the form of hydroxyapatite (133). Conversely, osteoclasts, through the secretion of hydrochloric acid and proteolytic enzymes, can dissolve minerals and lysis the bone matrix (134). Osteocytes are the main cellular component of bone tissue (135). Osteocytes control bone homoeostasis by maintaining the balance between the function of bone-forming osteoblasts and bone-resorbing osteoclasts (136). The common progenitors for osteoblasts and marrow adipocytes are bone marrow mesenchymal stem cells (BMMSCs) (137). The osteogenic and adipogenic differentiation of BMMSCs must maintain balance under accurate spatio-temporal control to defend skeletal health (138) (Fig. 2B). With ageing or other pathological stimuluses, BMMSCs have a disposition to differentiate into adipocytes, leading to the ascendent in marrow adiposity and gradual bone loss $(139,140)$. The variations in bone micro-architecture result in elevated skeletal fragility and an inclination to fracture (141). Recently, several studies have revealed different molecular mechanisms associated with osteoporosis, which are associated with m6A modification $(142,143)$.

A previous study revealed that the disruption of Mettl3 in bone marrow mesenchymal stem cells (MSCs) induces pathological features of osteoporosis in mice (143). It was demonstrated that the disfunction form of METTL3 resulted in destroyed bone formation, abnormal osteogenic differentiation and improved marrow adiposity (143). However, overexpression of METTL3 in BMMSCs protects mice against osteoporosis caused by oestrogen deficiency. Mechanistically, the $\mathrm{PTH} / \mathrm{Pth} 1 \mathrm{r}$ signalling axis is the target downstream pathway for m6A regulation in BMMSCs (143) (Fig. 3A). However, it 
A

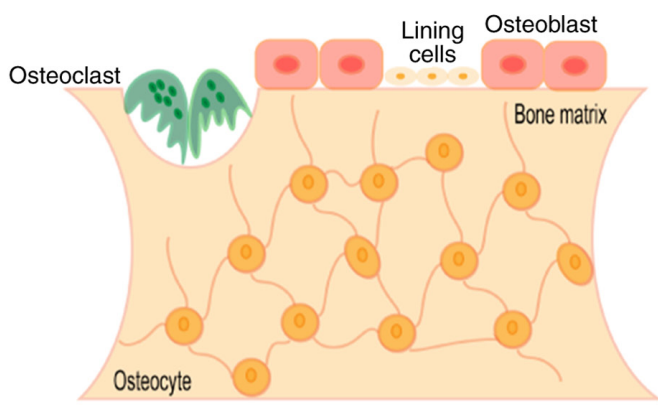

B

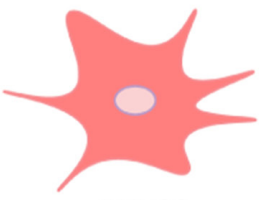

BMMSC

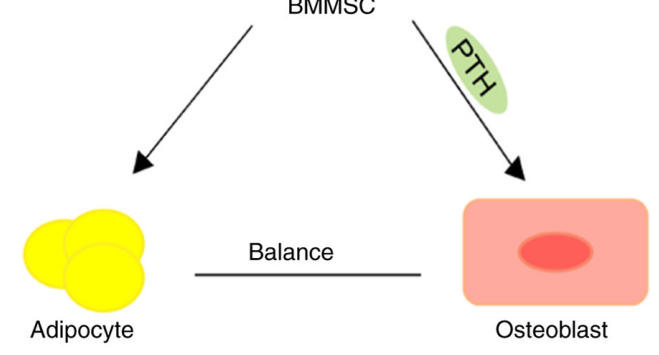

Figure 2. Representation of bone structure and differentiation of BMMSCs. (A) During bone remodelling, osteoclasts derived from hematopoietic stem cells resorb old or damaged bone. Osteoblasts derived from mesenchymal stem cells are recruited to damaged areas to replace bone removed by osteoclasts Osteocytes derived from osteoblasts suspend their activity when embedded in the bone matrix. (B) Mesenchymal stromal cells can differentiate into osteoblasts or adipocytes and maintain balance under accurate spatio-temporal controls to defend skeletal health. BMMSCs, bone marrow mesenchymal stem cells; PTH, parathyroid hormone.

has also been reported that METTL3 upregulates MYD88 expression by enhancing m6A modification to MYD88-RNA, consequently leading to the activation of $\mathrm{NF}-\kappa \mathrm{B}$, which is a repressor of osteogenesis, and inhibits osteogenic progression (144) (Fig. 3B). Furthermore, METTL3 expression increases in BMMSCs undergoing osteogenic induction, and disruption of METTL3 downregulates the expression of bone formation-related genes, such as Runx2 and Osterix (143). In addition, following METTL3 knockdown, the alkaline phosphatase activity and mineralised nodule formation also decline (145). Vascular endothelial growth factor (VEGF) plays important roles in bone formation and endothelial development $(146,147)$. It has been reported that METTL3 knockdown decreases VEGFA expression, as well as the expression level of its splice variants, including VEGFA-164 and VEGFA-188 in BMMSCs (145). Another study revealed that METTL3 disruption decreases m6A methylation levels and hampers osteogenic differentiation of BMMSCs, thus decreasing bone mass. In addition, METTL3 disorder can affect m6A methylation of RUNX2 and precursor (pre-) miR-320 (Fig. 3C) (148). METTL3 disruption suppresses this process and thus disturbs the normal osteogenic differentiation, which results in osteoporosis (148). Recently, a study reported that METTL3 expression increases during osteoclast differentiation, whose deficiency results in increased size but decreased bone-resorbing ability of osteoclasts through the mechanism involving Atp6v0d2 mRNA degradation mediated by YTHDF2 and TRAF6 mRNA nuclear export (149). This suggests that METTL3 may contribute to osteoporosis by regulating osteoclast differentiation (Fig. 3D).

Arginine-316 in human FTO corresponds to Arginine-313 in mice, which is essential for FTO catalytic activity (150). A previous study reported that FTO R313A/R313A mice not only decreased the body and bone length, which was associated with a substantial reduction in BMD and bone mineral content (BMC), but also notably abated the alkaline phosphatase activity, indicating osteoblast function (151). Peroxisome proliferator-activated receptor $\gamma(\operatorname{PPAR} \gamma)$ is a transcriptional factor that maintains the balance between adipocyte and osteoblast differentiation from BMMSCs, that is, accelerating the differentiation of adipocytes and inhibiting osteoblast differentiation (152). It has been reported that PPAR $\gamma$ mRNA is targeted and demethylated by FTO, which upregulates PPAR $\gamma$ mRNA expression, eventually promoting the differentiation of osteoporotic BMMSCs to adipocytes, and decreases bone formation in the process of osteoporosis (153) (Fig. 3E). Another study revealed that regardless of the mouse models lacking FTO globally or selectively, both exhibited age-related decreases in bone volume, in both the trabecular and cortical compartments (154). The mechanism demonstrated that FTO disruption in osteoblasts changes the Hsp70 transcripts (Hspala) and other genes involved in the DNA repair pathway containing conserved m6A motifs required for demethylation by FTO, thus affecting osteoblasts (154) (Fig. 3F). Furthermore, several FTO single nucleotide polymorphisms (SNPs) are associated with BMD variations in Chinese populations (155). In addition, miR-149-3p inhibits the differentiation of the adipogenic lineage and enhances the differentiation of the osteogenic lineage by targeting FTO (156) (Fig. 3G). Thus, FTO may be a novel candidate for osteoporosis (156).

Considering that inflammatory factors can hamper osteogenesis, studies have aimed to investigate the association between m6A, inflammation and osteoporosis. Several cytokines have been identified that participate in the development of osteoporosis, including RANKL, colony-stimulating factor (CSF)-1, interleukin-34 (157) and granulocyte-macrophage-CSF (158). A study revealed that osteoblast differentiation and Smad-dependent signalling is inhibited after disrupting METTL3 by stabilising Smad7 and Smurf1 mRNA transcripts, which is mediated by YTHDF2 (159). In addition, the production of proinflammatory cytokines increases following METTL3 deficiency by activating the MAPK signalling pathway to promote the osteoblast inflammatory response (60). Furthermore, YTHDF2 knockdown enhances the LPS-induced expression levels of IL-6, tumor necrosis factor (TNF)- $\alpha$, IL-1 $\beta$ and IL-12, which 
A

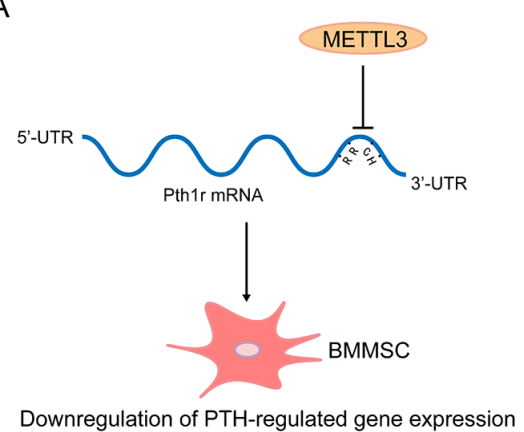

B

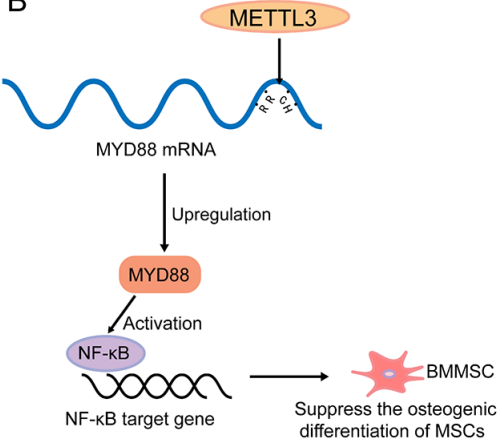

C

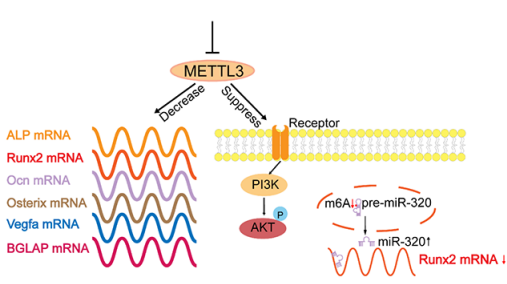

$\mathrm{D}$

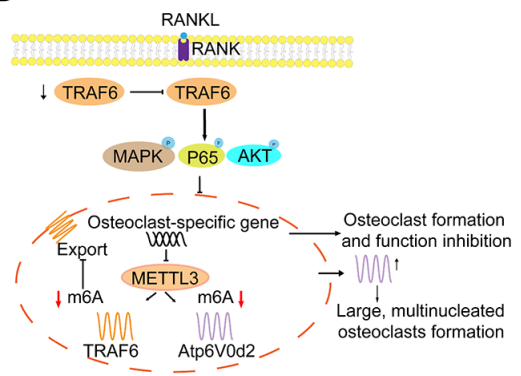

G

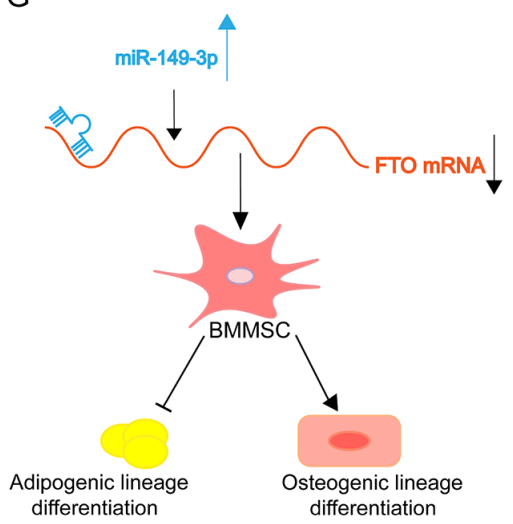

E

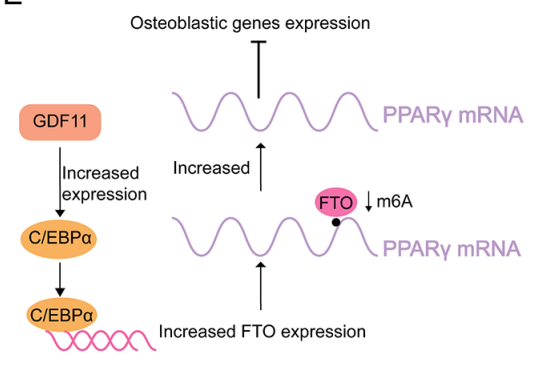

$\mathrm{F}$

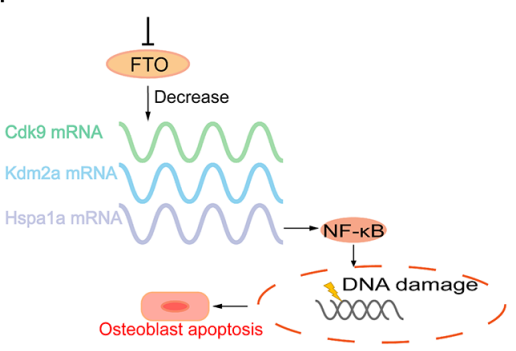

Figure 3. Schematic model of m6A in regulating osteoporosis. (A) METTL3 knockout decreases the translation efficiency of BM. BMMSCs lineage allocator Pth1r and disrupts PTH-induced osteogenic and adipogenic responses. (B) METTL3 positively regulates the expression of MYD88 by facilitating the modification of m6A methylation to MYD88-RNA and subsequently induces the activation of NF- $\mathrm{BB}$ to suppress osteogenic progression. (C) METTL3 deficiency results in decreased expression levels of RUNX2, Osterix, Ocn, VEGFA, BGLAP, and ALP, and suppresses the PI3K-Akt signalling pathway. METTL3 silencing also decreases RUNX2 mRNA levels through the suppression of the m6A of precursor (pre-)miR-320, which targets RUNX2. (D) METTL3 knockdown causes the retention of TRAF6 mRNA in the nucleus, which results in the inactivation of RANKL-induced signalling pathways, suppression of osteoclast-specific gene expression and inhibition of osteoclast formation and function. METTL3 knockdown upregulates Atp6v0d2 mRNA expression and stability and leads to the formation of large, multinucleated osteoclasts. (E) GDF11 upregulates C/EBP $\alpha$ to promote the expression of FTO during osteoporosis. Increased FTO levels results in the demethylation of Pparg mRNA and leads to an increase in Pparg mRNA levels, which affect the differentiation of BMMSCs (10). Disruption of FTO leads to changes in the transcripts of Hspala and other genes in the DNA repair pathway in osteoblasts. (F) FTO-deficiency-mediated downregulation of Hspala in osteoblasts activates the NF-кB signalling pathway and results in the increased susceptibility of osteoblasts genotoxic agents and increased rates of apoptosis. (G) miR-149-3p represses the expression of FTO genes by binding to the 3'-UTR of the FTO mRNA to decrease the adipogenic differentiation potential of BMMSCs and increase osteogenic differentiation potential. m6A, RNA N6-methyladenine; METTL, methyltransferase-like; BMMSCs, bone marrow mesenchymal stem cells; NF, nuclear factor; Runx2, runt-related transcription factor 2; VEGF, vascular endothelial factor; ALP, alkaline phosphatase; miR, microRNA; FTO, fat-mass and obesity-associated protein; UTR, untranslated region.

contributes to bone inflammation and osteoporosis through sophisticated mechanisms $(160,161)$.

\section{4. m6A and arthritis}

Arthritis is an inflammatory disease that occurs in several human joints and surrounding tissues. It is classified into dozens of diseases that are triggered by multiple pathological conditions, such as inflammation, infection, degeneration and trauma (162). The main clinical characteristics of arthritis include red, swollen, hot, painful, dysfunctional and deformed joints, which all result in joint disability and decreased quality of life (163). Osteoarthritis (121) and rheumatoid arthritis (32) are the most common types of arthritis with different pathophysiological mechanisms and exhibit similar clinical features. The role of epigenetics, particularly of RNA modification in arthritis, has attracted great interest.

$\mathrm{OA}$ is the most common chronic joint disease characterised by pain, stiffness and mobility difficulties (164). OA is caused by a complex interaction among diverse molecular 


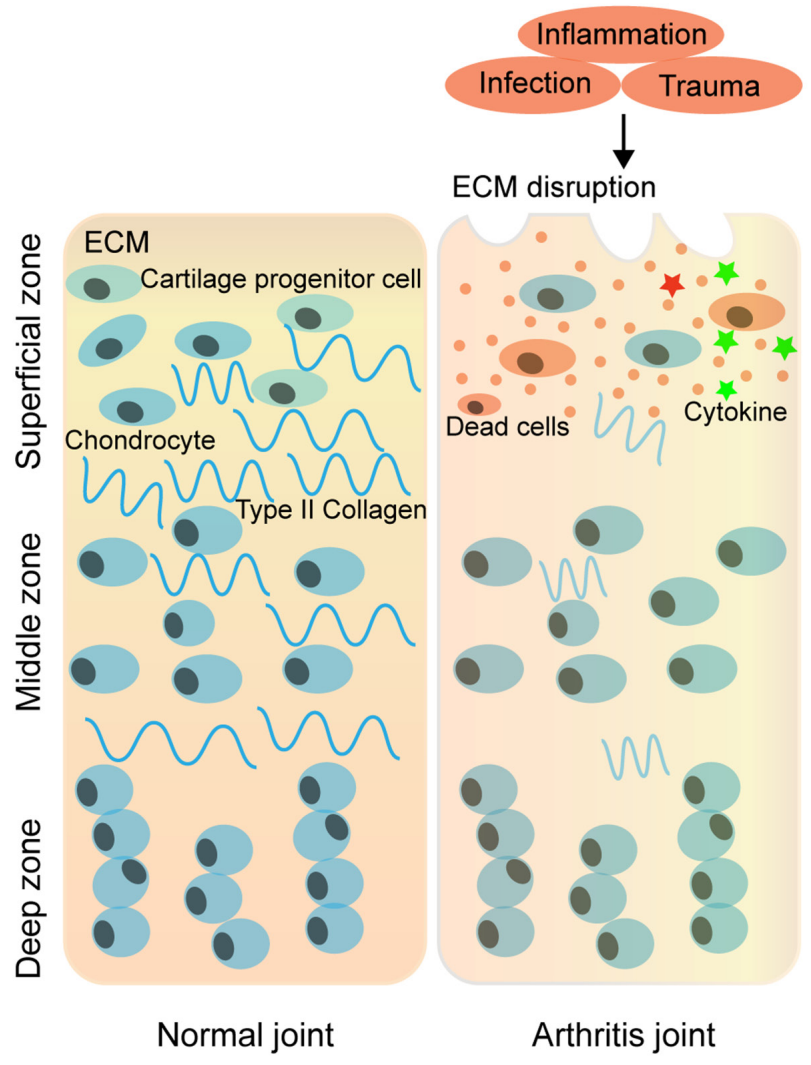

Figure 4. Schematic diagram of the ECM structure of articular cartilage under normal and arthritic conditions. The cartilage ECM is a dynamic network of proteins secreted by chondrocytes. In normal joints, the ECM is composed mainly of type II collagen and proteoglycans; however, with the occurrence of inflammation, trauma and ageing, the cell density decreases and the ECM in articular cartilages degenerates. As degeneration continues, the loss of matrix leads to the propagation of cell death and tissue degeneration, which manifest as arthritis. ECM, extracellular matrix.

factors involved in integrity, genetic susceptibility, local inflammation, mechanical forces and other cellular biochemical processes. The most probable cause of OA is damage to articular cartilage via physical forces $(165,166)$. Damage to articular cartilage may lead to degenerative OA in which several factors, including inflammatory response to various components of cartilage, are involved (167-170). Progressive cartilage degeneration is involved in chondrocyte reduction and in the variation of molecular components of chondrocytes in self-synthetized extracellular matrix (ECM) in the process of OA development (171) (Fig. 4). A study reported that following treatment of ATDC5 cells with IL-1 $\beta$, both the abundance of METTL3 mRNA and the ratio of m6A methylated mRNA of total mRNA was enhanced. Although disturbance of METTL3 lowered the proportion of IL-1 $\beta$-induced apoptosis, it inhibited IL-1 $\beta$-induced increased levels of inflammatory cytokines and activation of NF-kB signalling in chondrocytes (172). In addition, disruption of METTL3 improves destruction of the ECM by decreasing matrix metalloproteinase- 13 and collagen (Coll) X expression levels, and elevating the expression levels of Aggrecan and Coll II (172) (Fig. 5A). Simultaneously, OA is a degenerative disease of the synovial joint. The synovial membrane is responsible for the inflammatory response, which causes the release of macrophage-derived pro-inflammatory cytokines, such as RA, including IL-6 (173). A study revealed that suppressing the overexpression of IL-6 in synovial fibroblasts is a prospective way to hamper the development and progression of OA $(173,174)$. Thus, it is apparent that m6A also participates in OA by regulating several cytokines. The reasons for the occurrence of OA are complicated, and research on the association between m6A and OA is lacking; thus, further studies are required.

Multiple pathological factors contribute to the development of RA, including autoimmunity, various pathogen infections and genetic factors (175). A study revealed that METTL3 deficiency in mouse $\mathrm{T}$ cells disrupts $\mathrm{T}$ cell homoeostasis and differentiation (176), which implies that m6A has a potential effect on the occurrence and development of RA through the regulation of the immune system (Fig. 5B). Another study revealed that METTL3, but not other m6A methylation-related proteins, including METTL14, FTO, ALKBH5, YTHDF1 and YTHDF2, is upregulated in RA (177). Increased METTL3 expression is positively associated with CRP and ESR levels, which are the two main markers of RA disease activity. It has been reported that METTL3 participates in RA by hindering the proliferation and inflammatory response of macrophages (177). However, whether METTL3 mediates the progression and development of RA requires further investigation (177). Several studies have indicated that m6A-associated SNPs play essential roles in gene expression and mRNA homoeostasis, which may subsequently lead to the occurrence of disease $(178,179)$. The RA GWAS dataset identified several RA-associated m6A-SNPs, which may play regulatory roles in the pathogenesis of RA, and some of them were associated with the mRNA expression of local RA-related genes (178). Taken together, these findings provide insight into the association between SNPs and RA. However, further studies are required to determine the molecular mechanisms. RA is a systemic disease with several immunological events, and the key pathogenetic changes are the production of pro-inflammatory cytokines from macrophage-like synoviocytes, including IL-1, IL-6 and TNF (180). YTHDF2 disruption notably increases the expression levels of LPS-induced IL-6, TNF- $\alpha$, IL-1 $\beta$ and IL-12. Thus, m6A also participates in RA pathology by regulating several cytokines (160). Furthermore, synovium inflammation is involved in extensive activated $\mathrm{CD}^{+} \mathrm{T}$ cells (181), suggesting that disturbed homoeostasis of $\mathrm{CD}^{+} \mathrm{T}$ cells plays a critical role in the development of RA $(182,183)$. Since T cells mediate the adaptive immune response and contain several subgroups (184), the concrete details and molecular mechanisms require further investigation.

\section{5. m6A and osteosarcoma}

One of the most common and aggressive malignant bone tumours is OS (12), which mainly occurs in children and adolescents whose bones grow rapidly $(185,186)$; however, the molecular mechanisms underlying OS development and progression remain unclear. A study revealed that the levels of m6A methylated RNAs are considerably higher in human OS tissues and cell lines (187). Furthermore, METTL3 disruption hinders the proliferative, migratory and invasive abilities of OS cells (187). Further mechanistic studies have reported that METTL3 deficiency decreases m6A methylation and 
A

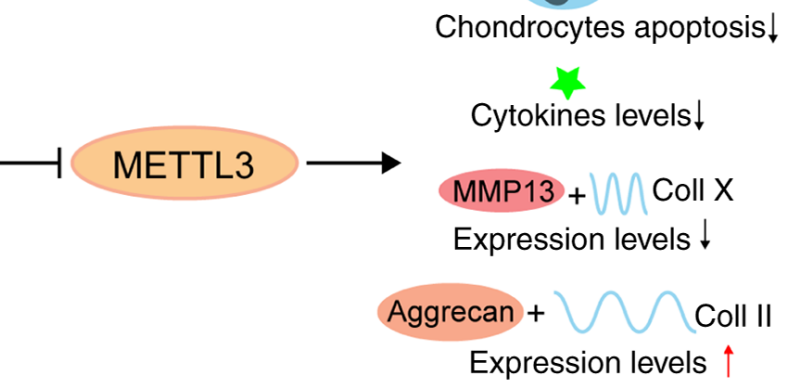

B

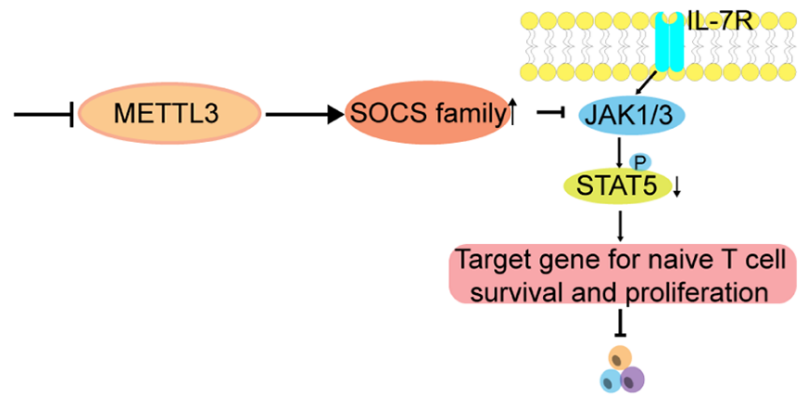

Naive T cells

Figure 5. Schematic model of $\mathrm{m6A}$ in regulating arthritis. (A) METTL3 knockdown decreases chondrocyte apoptosis rate and inflammatory cytokine levels. In addition, METTL3 knockdown promotes degradation of the extracellular matrix by suppressing the expression levels of MMP-13 and Coll X, while elevating the expression levels of Aggrecan and Coll II. (B) METTL3-deficiency-mediated loss of m6A leads to slower SOCS mRNA degradation and increased SOCS protein levels, thereby blocking the IL-7 pathway and eventually disrupting the differentiation and proliferation of naïve T cells. m6A, RNA N6-methyladenine; METTL, methyltransferase-like; MMP, matrix metalloproteinase; Coll, collagen; IL, interleukin.
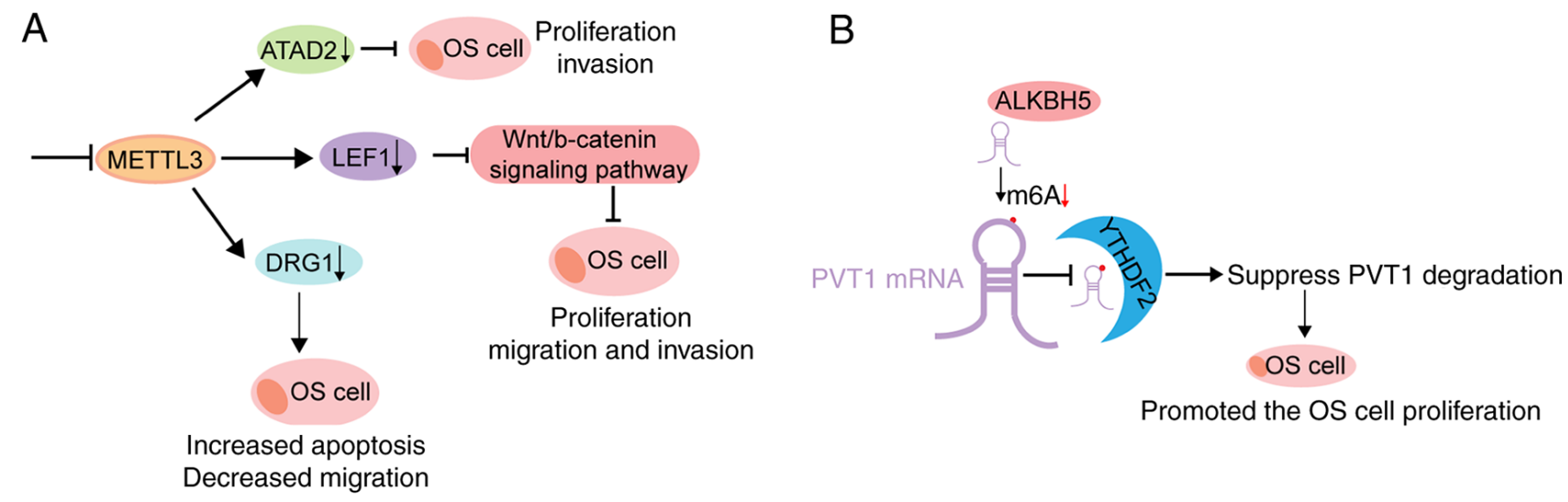

Promoted the OS cell proliferation

Figure 6. Schematic model of m6A in regulating osteosarcoma. (A) Upper: METTL3 knockdown inhibits the expression of ATPase family ATAD2, and the proliferation and invasion of OS cells. Middle: METTL3 knockdown decreases m6A methylation and total mRNA levels of LEF1, followed by the inhibition of the activity of Wnt/b-catenin signalling pathway, such that the proliferation, migration and invasion ability of OS cells are inhibited. Lower: METTL3 knockdown decreases m6A and Drg1 mRNA levels, thereby decreasing both the mRNA and protein levels of DRG1, such that the migration and colony formation abilities of OS cells are inhibited. (B) ALKBH5 decreases the m6A modification of PVT1, thereby inhibiting the binding of reader protein YTHDF2 in PVT1 and suppressing PVT1 degradation, such that OS cell proliferation and tumour growth are promoted. m6A, RNA N6-methyladenine; METTL, methyltransferase-like; ATAD2, AAA domain-containing protein 2; OS, osteosarcoma; LEF1, lymphoid enhancer-binding factor 1; DRG1, GTP-binding protein 1; ALHBH5, $\alpha$-ketoglutarate-dependent dioxygenase alkB homologue 5; YTHDF, YTH domain family.

mRNA levels of lymphoid enhancer-binding factor 1 (LEF1), a downstream factor of the Wnt signalling pathway (188), which is involved in the metastasis and chemoresistance of different types of cancer, including OS (188-190). In addition, LEF1 inhibits OS formation (187) (Fig. 6A). Knockdown of METTL3 and ELAVL1 (another m6A reader) decreases the expression levels of m6A and mRNA, and developmentally regulates GTP-binding protein 1 (DRG1), whose aberrant expression is associated with the development and progression of different tumours; attenuating DRG1 exerted OS-promoting effects (191) (Fig. 6A). Furthermore, a recent study revealed that METTL3 acts as an oncogene in the development and progression of OS (36). It has also been reported that METTL3 promotes the proliferation and metastasis of OS cells by targeting and regulating ATAD2 expression (36) (Fig. 6A). Furthermore, m6A modification may play a regulatory role by exerting biological effects on non-coding RNAs (192). In a study, ALKBH5-mediated m6A demethylation reportedly improved the stability of PVT1, a well-known oncogenic lncRNA, and accelerated the growth of OS (67) (Fig. 6B).

\section{Future prospects}

Currently, the number of different types of chemical modifications in RNA has reached $\sim 140(7)$. m6A is a pivotal epitranscriptomic modification in common orthopaedic diseases $(187,193,194)$. Several studies have revealed the underlying molecular mechanisms of m6A modifications in cancer $(51,63,195,196)$; however, research on the association between m6A and bone-related diseases is still lacking and should be addressed. In addition to the m6A-associated proteins mentioned, many other proteins, including writers (METTL5, METTL16, KIAA1429, RBM15, VIRMA and ZCCHC4) and readers (IGF2BP1, IGF2BP2, IGF2BP3 and eIF3), have been demonstrated to participate in the formation 
of m6A $(19,197)$. However, whether these proteins are involved in the pathogenesis and development of bone-related diseases remains unknown. m6A methyltransferase can methylate non-coding RNAs (198); however, studies on the interaction between non-coding RNAs and m6A in bone-related diseases are scarce. In addition, several bone-related diseases are associated with the activities of $\mathrm{m} 6 \mathrm{~A}$, such as epigenetic $\mathrm{m} 6 \mathrm{~A}$ modification, which plays an important role in the ossification of the ligamentum flavum (199). Recently, a review summarized the association between $\mathrm{m} 6 \mathrm{~A}$ and musculoskeletal disorders (200). However, the roles of m6A in T cell homoeostasis and differentiation remain unclear, both of which closely associated with the occurrence and development of osteoporosis, osteoarthritis, rheumatoid arthritis and osteosarcoma, which is a subject of novel and extensive research. Thus, further studies are required to determine the underlying cellular and molecular mechanisms of m6A in bone-related diseases. In conclusion, m6A may serve as a promising molecular target in regenerative medicine, bone tissue engineering and in the treatment of bone-related cancer.

\section{Acknowledgements}

Not applicable.

\section{Funding}

No funding was received.

\section{Availability of data and materials}

Not applicable.

\section{Authors' contributions}

$\mathrm{XZ}$ conceived and designed the present review. $\mathrm{YH}$ and $\mathrm{XZ}$ performed the data analysis and interpretation. $\mathrm{YH}$ and $\mathrm{XZ}$ drafted the initial manuscript. Data authentication is not applicable. Both authors have read and approved the final manuscript.

\section{Ethics approval and consent to participate}

Not applicable.

\section{Patient consent for publication}

Not applicable.

\section{Competing interests}

The authors declare that they have no competing interests.

\section{References}

1. Rits S, Olsen BR and Volloch V: Protein-encoding RNA to RNA information transfer in mammalian cells: RNA-dependent mRNA amplification. Identification of chimeric RNA intermediates and putative RNA end products. Ann Integr Mol Med 1: 23-47, 2019.

2. Howie H, Rijal CM and Ressler KJ: A review of epigenetic contributions to post-traumatic stress disorder. Dialogues Clin Neurosci 21: 417-428, 2019.
3. Holt CE and Schuman EM: The central dogma decentralized: New perspectives on RNA function and local translation in neurons. Neuron 80: 648-657, 2013.

4. Maydanovych O and Beal PA: Breaking the central dogma by RNA editing. Chem Rev 106: 3397-3411, 2006.

5. Thakur P, Estevez M, Lobue PA, Limbach PA and Addepalli B Improved RNA modification mapping of cellular non-coding RNAs using C- and U-specific RNases. Analyst 145: 816-827, 2020.

6. Shi H, Wei J and He C: Where, when, and how: Context-dependent functions of RNA methylation writers, readers, and erasers. Mol Cell 74: 640-650, 2019.

7. Roundtree IA, Evans ME, Pan T and He C: Dynamic RNA modifications in gene expression regulation. Cell 169: 1187-1200, 2017.

8. Liu J, Dou X, Chen C, Chen C, Liu C, Xu MM, Zhao S, Shen B, Gao Y, Han D and He C: $\mathrm{N}^{6}$-methyladenosine of chromosome-associated regulatory RNA regulates chromatin state and transcription. Science 367: 580-586, 2020.

9. Zeng C, Huang W, Li Y and Weng H: Roles of METTL3 in cancer: Mechanisms and therapeutic targeting. J Hematol Oncol 13: 117, 2020.

10. Shinoda K, Suda A, Otonari K, Futaki S and Imanishi M: Programmable RNA methylation and demethylation using PUF RNA binding proteins. Chem Commun (Camb) 56: 1365-1368, 2020.

11. Chen X, Chen X, Zhou Z, Mao Y, Wang Y, Ma Z, Xu W, Qin A and Zhang S: Nirogacestat suppresses RANKL-Induced osteoclast formation in vitro and attenuates LPS-Induced bone resorption in vivo. Exp Cell Res 382: 111470, 2019.

12. Dominissini D, Moshitch-Moshkovitz S, Schwartz S, Salmon-Divon M, Ungar L, Osenberg S, Cesarkas K, Jacob-Hirsch J, Amariglio N, Kupiec M, et al: Topology of the human and mouse m6A RNA methylomes revealed by m6A-seq. Nature 485: 201-206, 2012.

13. The RNA methyltransferase METTL3 promotes oncogene translation. Cancer Discov 6: 572, 2016.

14. Liu J, Yue Y, Han D, Wang X, Fu Y, Zhang L, Jia G, Yu M, Lu Z, Deng X, et al: A METTL3-METTL14 complex mediates mammalian nuclear RNA N6-adenosine methylation. Nat Chem Biol 10: 93-95, 2014

15. Chen Y, Peng C, Chen J, Chen D, Yang B, He B, Hu W, Zhang Y, Liu H, Dai L, et al: WTAP facilitates progression of hepatocellular carcinoma via m6A-HuR-dependent epigenetic silencing of ETS1. Mol Cancer 18: 127, 2019.

16. Li J, Zhu L, Shi Y, Liu J, Lin L and Chen X: m6A demethylase FTO promotes hepatocellular carcinoma tumorigenesis via mediating PKM2 demethylation. Am J Transl Res 11: 6084-6092, 2019.

17. Zheng G, Dahl JA, Niu Y, Fedorcsak P, Huang CM, Li CJ, Vågbø CB, Shi Y, Wang WL, Song SH, et al: ALKBH5 is a mammalian RNA demethylase that impacts RNA metabolism and mouse fertility. Mol Cell 49: 18-29, 2013.

18. Parker MT, Knop K, Sherwood AV, Schurch NJ, Mackinnon K, Gould PD, Hall AJ, Barton GJ and Simpson GG: Nanopore direct RNA sequencing maps the complexity of Arabidopsis mRNA processing and $\mathrm{m}^{6} \mathrm{~A}$ modification. eLife 9: e49658, 2020.

19. Liao S, Sun H and Xu C: YTH Domain: A family of $\mathrm{N}^{6}$-methyladenosine $\left(\mathrm{m}^{6} \mathrm{~A}\right)$ readers. Genomics Proteomics Bioinformatics 16: 99-107, 2018.

20. Zhao YL, Liu YH, Wu RF, Bi Z, Yao YX, Liu Q, Wang YZ and Wang $\mathrm{XX}$ : Understanding $\mathrm{m}^{6} \mathrm{~A}$ function through uncovering the diversity roles of YTH domain-containing proteins. Mol Biotechnol 61: 355-364, 2019.

21. Li F, Kennedy S, Hajian T, Gibson E, Seitova A, Xu C, Arrowsmith $\mathrm{CH}$ and Vedadi $\mathrm{M}$ : A radioactivity-based assay for screening human m6A-RNA methyltransferase, METTL3-METTL14 complex, and demethylase ALKBH5. J Biomol Screen 21: 290-297, 2016.

22. Liu Y and Santi DV: m5C RNA and m5C DNA methyl transferases use different cysteine residues as catalysts. Proc Natl Acad Sci USA 97: 8263-8265, 2000.

23. Roovers M, Wouters J, Bujnicki JM, Tricot C, Stalon V, Grosjean $\mathrm{H}$ and Droogmans L: A primordial RNA modification enzyme: The case of tRNA (m1A) methyltransferase. Nucleic Scids Res 32: 465-476, 2004.

24. Grabowski P: Physiology of bone. Endocr Dev 16: 32-48, 2009.

25. Scholtysek C, Kronke G and Schett G: Inflammation-associated changes in bone homeostasis. Inflamm Allergy Drug Targets 11: 188-195, 2012. 
26. Suominen H: Muscle training for bone strength. Aging Clin Exp Res 18: 85-93, 2006

27. Fu R, Lv WC, Xu Y, Gong MY, Chen XJ, Jiang N, Xu Y, Yao QQ, Di L, Lu T, et al: Endothelial ZEB1 promotes angiogenesis-dependent bone formation and reverses osteoporosis. Nat Commun 11: 460, 2020

28. Landete-Castillejos T, Kierdorf H, Gomez S, Luna S, García AJ, Cappelli J, Pérez-Serrano M, Pérez-Barbería J, Gallego L and Kierdorf U: Antlers-Evolution, development, structure, composition, and biomechanics of an outstanding type of bone. Bone 128: $115046,2019$.

29. Hassan MQ, Tye CE, Stein GS and Lian JB: Non-coding RNAs: Epigenetic regulators of bone development and homeostasis. Bone 81: 746-756, 2015

30. Bocheva G and Boyadjieva N: Epigenetic regulation of fetal bone development and placental transfer of nutrients: Progress for osteoporosis. Interdiscip Toxicol 4: 167-172, 2011.

31. Adamik J, Roodman GD and Galson DL: Epigenetic-based mechanisms of osteoblast suppression in multiple myeloma bone disease. JBMR Plus 3: e10183, 2019.

32. Marini F, Cianferotti L and Brandi ML: Epigenetic mechanisms in bone biology and osteoporosis: Can they drive therapeutic choices? Int J Mol Sci 17: 1329, 2016.

33. Ghayor $\mathrm{C}$ and Weber FE: Epigenetic regulation of bone remodeling and its impacts in osteoporosis. Int J Mol Sci 17: 1446, 2016

34. Montecino M, Stein G, Stein J, Zaidi K and Aguilar R: Multiple levels of epigenetic control for bone biology and pathology. Bone 81: 733-738, 2015.

35. Kobayashi M, Ohsugi M, Sasako T, Awazawa M, Umehara T, Iwane A, Kobayashi N, Okazaki Y, Kubota N, Suzuki R, et al: The RNA methyltransferase complex of WTAP, METTL3, and METTL14 regulates mitotic clonal expansion in adipogenesis Mol Cell Biol 38: e00116-18, 2018.

36. Zhou L, Yang C, Zhang N, Zhang X, Zhao T and Yu J: Silencing METTL3 inhibits the proliferation and invasion of osteosarcoma by regulating ATAD2. Biomed Pharmacother 125: 109964, 2020

37. Bujnicki JM, Feder M, Radlinska M and Blumenthal RM: Structure prediction and phylogenetic analysis of a functionally diverse family of proteins homologous to the MT-A70 subunit of the human mRNA:m(6)A methyltransferase. J Mol Evol 55: 431-444, 2002

38. Scholler E, Weichmann F, Treiber T, Ringle S, Treiber N, Flatley A, Feederle R, Bruckmann A and Meister G: Interactions, localization, and phosphorylation of the $\mathrm{m}^{6} \mathrm{~A}$ generating METTL3-METTL14-WTAP complex. RNA 24: 499-512, 2018.

39. Wang P, Doxtader KA and Nam Y: Structural basis for cooperative function of Mettl3 and Mettl14 methyltransferases. Mol Cell 63: 306-317, 2016.

40. Lence T, Paolantoni C, Worpenberg L and Roignant JY: Mechanistic insights into $\mathrm{m}^{6} \mathrm{~A}$ RNA enzymes. Biochim Biophys Acta Gene Regul Mech 1862: 222-229, 2019.

41. Haussmann IU, Bodi Z, Sanchez-Moran E, Mongan NP, Archer N, Fray RG and Soller M: $\mathrm{m}^{6} \mathrm{~A}$ potentiates Sxl alternative pre-mRNA splicing for robust drosophila sex determination. Nature 540: 301-304, 2016

42. Wang X, Zhao BS, Roundtree IA, Lu Z, Han D, Ma H, Weng X, Chen K, Shi H and He C: N(6)-methyladenosine modulates messenger RNA translation efficiency. Cell 161: 1388-1399, 2015.

43. Wang X, Lu Z, Gomez A, Hon GC, Yue Y, Han D, Fu Y, Parisien M, Dai Q, Jia G, et al: N6-methyladenosine-dependent regulation of messenger RNA stability. Nature 505: 117-120, 2014

44. Alarcon CR, Lee H, Goodarzi H, Halberg N and Tavazoie SF: N6-methyladenosine marks primary microRNAs for processing. Nature 519: 482-485, 2015.

45. Wang X, Feng J, Xue Y, Guan Z, Zhang D, Liu Z, Gong Z, Wang Q, Huang J, Tang C, et al: Structural basis of N(6)-adenosine methylation by the METTL3-METTL14 complex. Nature 534: 575-578, 2016

46. Meyer KD and Jaffrey SR: Rethinking $\mathrm{m}^{6} \mathrm{~A}$ readers, writers, and erasers. Annu Rev Cell Dev Biol 33: 319-342, 2017.

47. Geula S, Moshitch-Moshkovitz S, Dominissini D, Mansour AA, Kol N, Salmon-Divon M, Hershkovitz V, Peer E, Mor N, Manor YS, et al: Stem cells. m6A mRNA methylation facilitates resolution of naive pluripotency toward differentiation. Science 347: 1002-1006, 2015

48. Hongay CF and Orr-Weaver TL: Drosophila Inducer of MEiosis 4 (IME4) is required for Notch signaling during oogenesis. Proc Natl Acad Sci USA 108: 14855-14860, 2011.
49. Zhong S, Li H, Bodi Z, Button J, Vespa L, Herzog M and Fray RG: MTA is an Arabidopsis messenger RNA adenosine methylase and interacts with a homolog of a sex-specific splicing factor. Plant Cell 20: 1278-1288, 2008

50. Clancy MJ, Shambaugh ME, Timpte CS and Bokar JA: Induction of sporulation in Saccharomyces cerevisiae leads to the formation of N6-methyladenosine in mRNA: A potential mechanism for the activity of the IME4 gene. Nucleic Acids Res 30: 4509-4518, 2002.

51. Han J, Wang JZ, Yang X, Yu H, Zhou R, Lu HC, Yuan WB, Lu JC, Zhou ZJ, Lu Q, et al: METTL3 promote tumor proliferation of bladder cancer by accelerating pri-miR221/222 maturation in m6A-dependent manner. Mol Cancer 18: 110, 2019.

52. Choe J, Lin S, Zhang W, Liu Q, Wang L, Ramirez-Moya J, Du P, Kim W, Tang S, Sliz P, et al: mRNA circularization by METTL3-eIF3h enhances translation and promotes oncogenesis. Nature 561: 556-560, 2018.

53. Liu X, Liu L, Dong Z, Li J, Yu Y, Chen X, Ren F, Cui G and Sun R: Expression patterns and prognostic value of $\mathrm{m}^{6} \mathrm{~A}$-related genes in colorectal cancer. Am J Transl Res 11: 3972-3991, 2019

54. Visvanathan A, Patil V, Arora A, Hegde AS, Arivazhagan A, Santosh V and Somasundaram K: Essential role of METTL3-mediated $\mathrm{m}^{6} \mathrm{~A}$ modification in glioma stem-like cells maintenance and radioresistance. Oncogene 37: 522-533, 2018.

55. Wang H, Xu B and Shi J: N6-methyladenosine METTL3 promotes the breast cancer progression via targeting Bcl-2. Gene 722: 144076, 2020.

56. Vu LP, Pickering BF, Cheng Y, Zaccara S, Nguyen D, Minuesa G, Chou T, Chow A, Saletore Y, MacKay M, et al: The $\mathrm{N}^{6}$-methyladenosine $\left(\mathrm{m}^{6} \mathrm{~A}\right)$-forming enzyme METTL3 controls myeloid differentiation of normal hematopoietic and leukemia cells. Nat Med 23: 1369-1376, 2017.

57. Lin S, Liu J, Jiang W, Wang P, Sun C, Wang X, Chen Y and Wang H: METTL 3 promotes the proliferation and mobility of gastric cancer cells. Open Med (Wars) 14: 25-31, 2019.

58. Dahal U, Le K and Gupta M: RNA m6A methyltransferase METTL3 regulates invasiveness of melanoma cells by matrix metallopeptidase 2. Melanoma Res 29: 382-389, 2019.

59. Zheng W, Dong X, Zhao Y, Wang S, Jiang H, Zhang M, Zheng $X$ and Gu M: Multiple functions and mechanisms underlying the role of METTL3 in Human Cancers. Front Oncol 9: 1403, 2019.

60. Wu L, Wu D, Ning J, Liu W and Zhang D: Changes of N6-methyladenosine modulators promote breast cancer progression. BMC Cancer 19: 326, 2019.

61. Li X, Tang J, Huang W, Wang F, Li P, Qin C, Qin Z, Zou Q, Wei J, Hua L, et al: The M6A methyltransferase METTL3: Acting as a tumor suppressor in renal cell carcinoma. Oncotarget 8: 96103-96116, 2017.

62. Wei W, Huo B and Shi X: miR-600 inhibits lung cancer via downregulating the expression of METTL3. Cancer Manag Res 11: 1177-1187, 2019.

63. Zhang C, Zhang M, Ge S, Huang W, Lin X, Gao J, Gong J and Shen L: Reduced m6A modification predicts malignant phenotypes and augmented Wnt/PI3K-Akt signaling in gastric cancer. Cancer Med 8: 4766-4781, 2019.

64. Iyer LM, Zhang D and Aravind L: Adenine methylation in eukaryotes: Apprehending the complex evolutionary history and functional potential of an epigenetic modification. Bioessays 38: 27-40, 2016.

65. Liu X, Qin J, Gao T, Li C, Chen X, Zeng K, Xu M, He B, Pan B, $\mathrm{Xu}$ X, et al: Analysis of METTL3 and METTL14 in hepatocellular carcinoma. Aging (Albany NY) 12: 21638-21659, 2020.

66. Buker SM, Gurard-Levin ZA, Wheeler BD, Scholle MD, Case AW, Hirsch JL, Ribich S, Copeland RA and Boriack-Sjodin PA: A mass spectrometric assay of METTL3/METTL14 methyltransferase activity. SLAS Discov 25: 361-371, 2020

67. Chen X, Xu M, Xu X, Zeng K, Liu X, Pan B, Li C, Sun L, Qin J, $\mathrm{Xu}$ T, et al: METTL14-mediated N6-methyladenosine modification of SOX4 mRNA inhibits tumor metastasis in colorectal cancer. Mol Cancer 19: 106, 2020.

68. Gong PJ, Shao YC, Yang Y, Song WJ, He X, Zeng YF, Huang SR, Wei L and Zhang JW: Analysis of N6-methyladenosine methyltransferase reveals METTL14 and ZC3H13 as tumor suppressor genes in breast cancer. Front Oncol 10: 578963, 2020.

69. Gu C, Wang Z, Zhou N, Li G, Kou Y, Luo Y, Wang Y, Yang J and Tian F: Mettl14 inhibits bladder TIC self-renewal and bladder tumorigenesis through $\mathrm{N}^{6}$-methyladenosine of Notch1. Mol Cancer 18: 168, 2019. 
70. Weng H, Huang H, Wu H, Qin X, Zhao BS, Dong L, Shi H, Skibbe J, Shen C, Hu C, et al: METTL14 inhibits hematopoietic stem/progenitor differentiation and promotes leukemogenesis via mRNA m6 A modification. Cell Stem Cell 22: 191-205 e9, 2018.

71. Ping XL, Sun BF, Wang L, Xiao W, Yang X, Wang WJ, Adhikari S, Shi Y, Lv Y, Chen YS, et al: Mammalian WTAP is a regulatory subunit of the RNA N6-methyladenosine methyltransferase. Cell Res 24: 177-189, 2014.

72. Schwartz S, Mumbach MR, Jovanovic M, Wang T, Maciag K, Bushkin GG, Mertins $P$, Ter-Ovanesyan D, Habib N, Cacchiarelli D, et al: Perturbation of $\mathrm{m} 6 \mathrm{~A}$ writers reveals two distinct classes of mRNA methylation at internal and 5' sites. Cell Rep 8: 284-296, 2014

73. Sorci M, Ianniello Z, Cruciani S, Larivera S, Ginistrelli LC, Capuano E, Marchioni M, Fazi F and Fatica A: METTL3 regulates WTAP protein homeostasis. Cell Death Dis 9: 796, 2018.

74. Li H, Su Q, Li B, Lan L, Wang C, Li W, Wang G, Chen W, He Y and Zhang C: High expression of WTAP leads to poor prognosis of gastric cancer by influencing tumour-associated T lymphocyte infiltration. J Cell Mol Med 24: 4452-4465, 2020.

75. Bansal H, Yihua Q, Iyer SP, Ganapathy S, Proia DA, Penalva LO, Uren PJ, Suresh U, Carew JS, Karnad AB, et al: WTAP is a nove oncogenic protein in acute myeloid leukemia. Leukemia 28 $1171-1174,2014$

76. Horiuchi K, Umetani M, Minami T, Okayama H, Takada S, Yamamoto M, Aburatani H, Reid PC,Housman DE,Hamakubo T and Kodama T: Wilms' tumor 1-associating protein regulates G2/M transition through stabilization of cyclin A2 mRNA. Proc Natl Acad Sci USA 103: 17278-17283, 2006.

77. Wen J, Lv R, Ma H, Shen H, He C, Wang J, Jiao F, Liu H, Yang P, Tan $\mathrm{L}$, et al: Zc3h 13 regulates nuclear RNA $\mathrm{m}^{6} \mathrm{~A}$ methylation and mouse embryonic stem cell self-renewal. Mol Cell 69: 1028-1038 e6, 2018.

78. Zhu D, Zhou J, Zhao J, Jiang G, Zhang X, Zhang Y and Dong M: $\mathrm{ZC} 3 \mathrm{H} 13$ suppresses colorectal cancer proliferation and invasion via inactivating Ras-ERK signaling. J Cell Physiol 234: 8899-8907, 2019.

79. Chen J, Yu K, Zhong G and Shen W: Identification of a $\mathrm{m}^{6} \mathrm{~A}$ RNA methylation regulators-based signature for predicting the prognosis of clear cell renal carcinoma. Cancer Cell Int 20: 157, 2020

80. Liu T, Li C, Jin L, Li C and Wang L: The prognostic value of m6A RNA methylation regulators in colon adenocarcinoma. Med Sci Monit 25: 9435-9445, 2019.

81. Jia G, Fu Y, Zhao X, Dai Q, Zheng G, Yang Y, Yi C, Lindahl T, Pan T, Yang YG and He C: N6-methyladenosine in nuclear RNA is a major substrate of the obesity-associated FTO. Nat Chem Biol 7: 885-887, 2011

82.Zhou J, Wan J, Gao X, Zhang X, Jaffrey SR and Qian SB: Dynamic m(6)A mRNA methylation directs translational control of heat shock response. Nature 526: 591-594, 2015.

83. Dina C, Meyre D, Gallina S, Durand E, Körner A, Jacobson P, Carlsson LM, Kiess W, Vatin V, Lecoeur C, et al: Variation in FTO contributes to childhood obesity and severe adult obesity. Nat Genet 39: 724-726, 2007.

84. Frayling TM, Timpson NJ, Weedon MN, Zeggini E, Freathy RM, Lindgren CM, Perry JR, Elliott KS, Lango H, Rayner NW, et al: A common variant in the FTO gene is associated with body mass index and predisposes to childhood and adult obesity. Science 316: 889-894, 2007

85. Niu Y, Lin Z, Wan A, Chen H, Liang H, Sun L, Wang Y, Li X, Xiong XF, Wei B, et al: RNA N6-methyladenosine demethylase FTO promotes breast tumor progression through inhibiting BNIP3. Mol Cancer 18: 46, 2019.

86. Li Z, Weng H, Su R, Weng X, Zuo Z, Li C, Huang H, Nachtergaele S, Dong L, Hu C, et al: FTO plays an oncogenic role in acute myeloid leukemia as a $\mathrm{N}^{6}$-Methyladenosine RNA demethylase. Cancer Cell 31: 127-141, 2017.

87. Yang S, Wei J, Cui YH, Park G, Shah P, Deng Y, Aplin AE, Lu Z, Hwang S, He C and He YY: ${ }^{6} \mathrm{~A}$ mRNA demethylase FTO regulates melanoma tumorigenicity and response to anti-PD-1 blockade. Nat Commun 10: 2782, 2019.

88. Li J, Han Y, Zhang H, Qian Z, Jia W, Gao Y, Zheng H and Li B: The m6A demethylase FTO promotes the growth of lung cancer cells by regulating the m6A level of USP7 mRNA. Biochem Biophys Res Commun 512: 479-485, 2019.

89. Baltz AG, Munschauer M, Schwanhausser B, Vasile A, Murakawa Y, Schueler M, Youngs N, Penfold-Brown D Drew K, Milek M, et al: The mRNA-bound proteome and its global occupancy profile on protein-coding transcripts. Mol Cell 46: 674-690, 2012.
90. Fedeles BI, Singh V, Delaney JC, Li D and Essigmann JM: The AlkB family of $\mathrm{Fe}(\mathrm{II}) / \alpha$-Ketoglutarate-dependent dioxygenases Repairing nucleic acid alkylation damage and beyond. J Biol Chem 290: 20734-20742, 2015.

91. Pilzys T, Marcinkowski M, Kukwa W, Garbicz D, Dylewska M, Ferenc K, Mieczkowski A, Kukwa A, Migacz E, Wołosz D, et al: ALKBH overexpression in head and neck cancer: Potential target for novel anticancer therapy. Sci Rep 9: 13249, 2019.

92. Guo X, Li K, Jiang W, Hu Y, Xiao W, Huang Y, Feng Y, Pan Q and Wan R: RNA demethylase ALKBH5 prevents pancreatic cancer progression by posttranscriptional activation of PER1 in an m6A-YTHDF2-dependent manner. Mol Cancer 19: 91, 2020

93. Shen C, Sheng Y, Zhu AC, Robinson S, Jiang X, Dong L, Chen H, Su R, Yin Z, Li W, et al: RNA demethylase ALKBH5 selectively promotes tumorigenesis and cancer stem cell self-renewal in acute myeloid leukemia. Cell Stem Cell 27: 64-80.e9, 2020.

94. Zhang S, Zhao BS, Zhou A, Lin K, Zheng S, Lu Z, Chen Y, Sulman EP, Xie K, Bögler O, et al: m6A demethylase ALKBH5 maintains tumorigenicity of glioblastoma Stem-like cells by sustaining FOXM1 expression and cell proliferation program. Cancer Cell 31: 591-606.e6, 2017.

95. Zhu Z, Qian Q, Zhao X, Ma L and Chen P: $\mathrm{N}^{6}$-methyladenosine ALKBH5 promotes non-small cell lung cancer progress by regulating TIMP3 stability. Gene 731: 144348, 2020.

96. Zhang J, Guo S, Piao HY, Wang Y, Wu Y, Meng XY, Yang D, Zheng ZC and Zhao Y: ALKBH5 promotes invasion and metastasis of gastric cancer by decreasing methylation of the lncRNA NEAT1. J Physiol Biochem 75: 379-389, 2019.

97. Ueda Y, Ooshio I, Fusamae Y, Kitae K, Kawaguchi M, Jingushi K, Hase H, Harada K, Hirata K and Tsujikawa K: AlkB homolog 3-mediated tRNA demethylation promotes protein synthesis in cancer cells. Sci Rep 7: 42271, 2017

98. Mohan M, Akula D, Dhillon A, Goyal A and Anindya R: Human RAD51 paralogue RAD51C fosters repair of alkylated DNA by interacting with the ALKBH3 demethylase. Nucleic Acids Res 47: 11729-11745, 2019.

99. Chen Z, Qi M, Shen B, Luo G, Wu Y, Li J, Lu Z, Zheng Z, Dai Q and Wang H: Transfer RNA demethylase ALKBH3 promotes cancer progression via induction of tRNA-derived small RNAs. Nucleic Acids Res 47: 2533-2545, 2019

100. Fu Y, Dominissini D, Rechavi G and He C: Gene expression regulation mediated through reversible $\mathrm{m}^{6} \mathrm{~A}$ RNA methylation. Nat Rev Genet 15: 293-306, 2014.

101. Yue Y, Liu J and He C: RNA N6-methyladenosine methylation in post-transcriptional gene expression regulation. Genes Dev 29: 1343-1355, 2015.

102. Zhu T, Roundtree IA, Wang P, Wang X, Wang L, Sun C, Tian Y, Li J, He C and $\mathrm{Xu} \mathrm{Y:} \mathrm{Crystal} \mathrm{structure} \mathrm{of} \mathrm{the} \mathrm{YTH}$ domain of YTHDF2 reveals mechanism for recognition of N6-methyladenosine. Cell Res 24: 1493-1496, 2014.

103. Lee Y, Choe J, Park OH and Kim YK: Molecular mechanisms driving mRNA degradation by $\mathrm{m}^{6} \mathrm{~A}$ modification. Trends Genet 36: 177-188, 2020.

104. Li M, Zhao X, Wang W, Shi H, Pan Q, Lu Z, Perez SP, Suganthan R, He C, Bjørås M and Klungland A: Ythdf2-mediated $\mathrm{m}^{6} \mathrm{~A}$ mRNA clearance modulates neural development in mice. Genome Biol 19: 69, 2018.

105. Wang H, Zuo H, Liu J, Wen F, Gao Y, Zhu X, Liu B, Xiao F, Wang W, Huang G, et al: Loss of YTHDF2-mediated $\mathrm{m}^{6} \mathrm{~A}$-dependent $\mathrm{mRNA}$ clearance facilitates hematopoietic stem cell regeneration. Cell Res 28: 1035-1038, 2018.

106. Chen M, Wei L, Law CT, Tsang FH, Shen J, Cheng CL, Tsang LH, Ho DW, Chiu DK, Lee JM, et al: RNA N6-methyladenosine methyltransferase-like 3 promotes liver cancer progression through YTHDF2-dependent posttranscriptional silencing of SOCS2. Hepatology 67: 2254-2270, 2018.

107. Huang T, Liu Z, Zheng Y, Feng T, Gao Q and Zeng W: YTHDF2 promotes spermagonial adhesion through modulating MMPs decay via $\mathrm{m}^{6} \mathrm{~A} / \mathrm{mRNA}$ pathway. Cell Death Dis 11: 37, 2020.

108. Meyer KD, Patil DP, Zhou J, Zinoviev A, Skabkin MA, Elemento O, Pestova TV, Qian SB and Jaffrey SR: 5'UTR m(6)A promotes cap-independent translation. Cell 163: 999-1010, 2015.

109. Hu L, Wang J, Huang H, Yu Y, Ding J, Yu Y, Li K, Wei D, Ye Q Wang $\mathrm{F}$, et al: YTHDF1 regulates pulmonary hypertension through translational control of MAGED1. Am J Respir Crit Care Med 203: 1158-1172, 2021.

110. Shi H, Zhang X, Weng YL, Lu Z, Liu Y, Lu Z, Li J, Hao P, Zhang Y,Zhang F, et al: $\mathrm{m}^{6} \mathrm{~A}$ facilitates hippocampus-dependent learning and memory through YTHDF1. Nature 563: 249-253, 2018 . 
111. Nishizawa Y, Konno M, Asai A, Koseki J, Kawamoto K, Miyoshi N, Takahashi H, Nishida N, Haraguchi N, Sakai D, et al: Oncogene c-Myc promotes epitranscriptome $\mathrm{m}^{6} \mathrm{~A}$ reader YTHDF1 expression in colorectal cancer. Oncotarget 9: 7476-7486, 2018.

112. Zhao X, Chen Y, Mao Q, Jiang X, Jiang W, Chen J, Xu W, Zhong L and Sun X: Overexpression of YTHDF1 is associated with poor prognosis in patients with hepatocellular carcinoma. Cancer Biomark 21: 859-868, 2018.

113. Zhang Y, Wang X, Zhang X, Wang J, Ma Y, Zhang L and Cao X: RNA-binding protein YTHDF3 suppresses interferon-dependent antiviral responses by promoting FOXO3 translation. Proc Natl Acad Sci USA 116: 976-981, 2019.

114. Ni W, Yao S, Zhou Y, Liu Y, Huang P, Zhou A, Liu J, Che L and Li J: Long noncoding RNA GAS5 inhibits progression of colorectal cancer by interacting with and triggering YAP phosphorylation and degradation and is negatively regulated by the $\mathrm{m}^{6} \mathrm{~A}$ reader YTHDF3. Mol Cancer 18: 143, 2019.

115. Jurczyszak D, Zhang W, Terry SN, Kehrer T, Bermúdez González MC, McGregor E, Mulder LCF, Eckwahl MJ, Pan T and Simon V: HIV protease cleaves the antiviral m6A reader protein YTHDF3 in the viral particle. PLoS Pathog 16: e1008305, 2020.

116. Xiao W, Adhikari S, Dahal U, Chen YS, Hao YJ, Sun BF, Sun HY, Li A, Ping XL, Lai WY, et al: Nuclear m(6)A reader YTHDC1 regulates mRNA splicing. Mol Cell 61: 507-519, 2016

117. Luxton HJ, Simpson BS, Mills IG, Brindle NR, Ahmed Z, Stavrinides V, Heavey S, Stamm S and Whitaker HC: The oncogene metadherin interacts with the known splicing proteins YTHDC1, Sam68 and T-STAR and plays a novel role in alternative mRNA splicing. Cancers (Basel) 11: 1233, 2019.

118. Kasowitz SD, Ma J, Anderson SJ, Leu NA, Xu Y, Gregory BD, Schultz RM and Wang PJ: Nuclear m6A reader YTHDC1 regulates alternative polyadenylation and splicing during mouse oocyte development. PLoS Genet 14: e1007412, 2018.

119. Mao Y, Dong L, Liu XM, Guo J, Ma H, Shen B and Qian SB $\mathrm{m}^{6} \mathrm{~A}$ in mRNA coding regions promotes translation via the RNA helicase-containing YTHDC2. Nat Commun 10: 5332, 2019.

120. Tanabe A, Tanikawa K, Tsunetomi M, Takai K, Ikeda H, Konno J, Torigoe T, Maeda H, Kutomi G, Okita K, et al: RNA helicase YTHDC2 promotes cancer metastasis via the enhancement of the efficiency by which HIF-1 $\alpha$ mRNA is translated. Cancer Lett 376: 34-42, 2016.

121. Kretschmer J, Rao H, Hackert P, Sloan KE, Hobartner C and Bohnsack MT: The $\mathrm{m}^{6} \mathrm{~A}$ reader protein YTHDC2 interacts with the small ribosomal subunit and the 5'-3' exoribonuclease XRN1. RNA 24: 1339-1350, 2018

122. Nakano M, Ondo K, Takemoto S, Fukami T and Nakajima M: Methylation of adenosine at the $\mathrm{N}^{6}$ position post-transcriptionally regulates hepatic P450s expression. Biochem Pharmacol 171: 113697, 2020.

123. Bailey AS, Batista PJ, Gold RS, Chen YG, de Rooij DG, Chang HY and Fuller MT: The conserved RNA helicase YTHDC2 regulates the transition from proliferation to differentiation in the germline. eLife 6: e26116, 2017.

124. Tanabe A, Konno J, Tanikawa K and Sahara H: Transcriptional machinery of TNF- $\alpha$-inducible YTH domain containing 2 (YTHDC2) gene. Gene 535: 24-32, 2014

125. Alarcon CR, Goodarzi H, Lee H, Liu X, Tavazoie S and Tavazoie SF: HNRNPA2B1 is a mediator of $\mathrm{m}(6) \mathrm{A}$-dependent nuclear RNA processing events. Cell 162: 1299-1308, 2015.

126. Huang H, Weng H, Sun W, Qin X, Shi H, Wu H, Zhao BS Mesquita A, Liu C, Yuan CL, et al: Recognition of RNA $\mathrm{N}^{6}$-methyladenosine by IGF2BP proteins enhances mRNA stability and translation. Nat Cell Biol 20: 285-295, 2018.

127. Srivastava $\mathrm{M}$ and Deal C: Osteoporosis in elderly: Prevention and treatment. Clin Geriatr Med 18: 529-555, 2002

128. Langdahl BL: Overview of treatment approaches to osteoporosis. Br J Pharmacol 178: 1891-1906, 2021.

129. Rosen CJ and Bouxsein ML: Mechanisms of disease: Is osteoporosis the obesity of bone? Nat Clin Pract Rheumatol 2: 35-43, 2006.

130. Raisz LG: Pathogenesis of osteoporosis: Concepts, conflicts, and prospects. J Clin Invest 115: 3318-3325, 2005.

131. Palmieri D, Valli M, Viglio S, Ferrari N, Ledda B, Volta C and Manduca P: Osteoblasts extracellular matrix induces vessel like structures through glycosylated collagen I. Exp Cell Res 316 789-799, 2010.
132. DeNichilo MO, Shoubridge AJ, Panagopoulos V, Liapis V, Zysk A, Zinonos I, Hay S, Atkins GJ, Findlay DM and Evdokiou A: Peroxidase enzymes regulate collagen biosynthesis and matrix mineralization by cultured human osteoblasts. Calcif Tissue Int 98: 294-305, 2016

133. Long F: Building strong bones: Molecular regulation of the osteoblast lineage. Nat Rev Mol Cell Biol 13: 27-38, 2011.

134. Boyle WJ, Simonet WS and Lacey DL: Osteoclast differentiation and activation. Nature 423: 337-342, 2003

135. Villaseñor A, Aedo-Martín D, Obeso D, Erjavec I, Rodríguez-Coira J, Buendía I, Ardura JA, Barbas C and Gortazar AR: Metabolomics reveals citric acid secretion in mechanically-stimulated osteocytes is inhibited by high glucose. Sci Rep 9: 2295, 2019.

136. Dallas SL, Prideaux M and Bonewald LF: The osteocyte: An endocrine cell... and more. Endocr Rev 34: 658-690, 2013.

137. Chen Q, Shou P, Zheng C, Jiang M, Cao G, Yang Q, Cao J, Xie N, Velletri T, Zhang X, et al: Fate decision of mesenchymal stem cells: Adipocytes or osteoblasts? Cell Death Differ 23: $1128-1139,2016$

138. Kawai M, Devlin MJ and Rosen CJ: Fat targets for skeletal health. Nat Rev Rheumatol 5: 365-372, 2009.

139. Rosen CJ, Ackert-Bicknell C, Rodriguez JP and Pino AM: Marrow fat and the bone microenvironment: Developmental, functional, and pathological implications. Crit Rev Eukaryot Gene Expr 19: 109-124, 2009.

140. Scheller EL and Rosen CJ: What's the matter with MAT? Marrow adipose tissue, metabolism, and skeletal health. Ann N Y Acad Sci 1311: 14-30, 2014

141. Garcia-Gomez MC and Vilahur G: Osteoporosis and vascular calcification: A shared scenario. Clin Investig Arterioscler 32: 33-42, 2020.

142. Chen X, Hua W, Huang X, Chen Y, Zhang J and Li G: Regulatory role of RNA $\mathrm{N}^{6}$-methyladenosine modification in bone biology and osteoporosis. Front Endocrinol (Lausanne) 10: 911, 2019.

143. Wu Y, Xie L, Wang M, Xiong Q, Guo Y, Liang Y, Li J, Sheng R, Deng P, Wang Y, et al: Mettl3-mediated $\mathrm{m}^{6} \mathrm{~A}$ RNA methylation regulates the fate of bone marrow mesenchymal stem cells and osteoporosis. Nat Commun 9: 4772, 2018.

144. Yu J, Shen L, Liu Y, Ming H, Zhu X, Chu M and Lin J: The m6A methyltransferase METTL3 cooperates with demethylase ALKBH5 to regulate osteogenic differentiation through NF- $\kappa B$ signaling. Mol Cell Biochem 463: 203-210, 2020.

145. Tian C, Huang Y, Li Q, Feng Z and Xu Q: Mettl3 regulates osteogenic differentiation and alternative splicing of vegfa in bone marrow mesenchymal stem cells. Int J Mol Sci 20: 551, 2019.

146. Busilacchi A, Gigante A, Mattioli-Belmonte M, Manzotti S and Muzzarelli RA: Chitosan stabilizes platelet growth factors and modulates stem cell differentiation toward tissue regeneration. Carbohydr Polym 98: 665-676, 2013.

147. Hu K and Olsen BR: Osteoblast-derived VEGF regulates osteoblast differentiation and bone formation during bone repair. J Clin Invest 126: 509-526, 2016.

148. Yan G, Yuan Y, He M, Gong R, Lei H, Zhou H, Wang W, Du W, MaT,LiuS, et al: $\mathrm{m}^{6}$ A methylation of precursor-miR-320/RUNX2 controls osteogenic potential of bone marrow-derived mesenchymal stem cells. Mol Ther Nucleic Acids 19: 421-436, 2020.

149. Li D, Cai L, Meng R, Feng Z and Xu Q: METTL3 modulates osteoclast differentiation and function by controlling RNA stability and nuclear export. Int J Mol Sci 21: 1660, 2020.

150. Gerken T, Girard CA, Tung YC, Webby CJ, Saudek V, Hewitson KS, Yeo GS, McDonough MA, Cunliffe S, McNeill LA, et al: The obesity-associated FTO gene encodes a 2-oxoglutarate-dependent nucleic acid demethylase. Science 318: 1469-1472, 2007

151. Eyre DR: Bone biomarkers as tools in osteoporosis management. Spine (Phila Pa 1976) 22 (24 Suppl): 17S-24S, 1997.

152. Takada I, Kouzmenko AP and Kato S: Wnt and PPARgamma signaling in osteoblastogenesis and adipogenesis. Nat Rev Rheumatol 5: 442-447, 2009.

153. Shen GS, Zhou HB, Zhang H, Chen B, Liu ZP, Yuan Y, Zhou XZ and Xu YJ: The GDF11-FTO-PPAR $\gamma$ ax is controls the shift of osteoporotic MSC fate to adipocyte and inhibits bone formation during osteoporosis. Biochim Biophys Acta Mol Basis Dis 1864: 3644-3654, 2018

154.Zhang Q, Riddle RC, Yang Q, Rosen CR, Guttridge DC, Dirckx N, Faugere MC, Farber CR and Clemens TL: The RNA demethylase FTO is required for maintenance of bone mass and functions to protect osteoblasts from genotoxic damage. Proc Natl Acad Sci USA 116: 17980-17989, 2019. 
155. Guo Y, Liu H, Yang TL, Li SM, Li SK, Tian Q, Liu YJ and Deng HW: The fat mass and obesity associated gene, FTO, is also associated with osteoporosis phenotypes. PLoS One 6: e27312, 2011

156. Li Y, Yang F, Gao M, Gong R, Jin M, Liu T, Sun Y, Fu Y, Huang Q, Zhang W, et al: miR-149-3p regulates the switch between adipogenic and osteogenic differentiation of BMSCs by targeting FTO. Mol Ther Nucleic Acids 17: 590-600, 2019.

157. Mannerstrom B, Kornilov R, Abu-Shahba AG, Chowdhury IM, Sinha S, Seppänen-Kaijansinkko R and Kaur S: Epigenetic alterations in mesenchymal stem cells by osteosarcoma-derived extracellular vesicles. Epigenetics 14: 352-364, 2019.

158. Lorenzo J: Cytokines and bone: Osteoimmunology. Handb Exp Pharmacol 262: 177-230, 2020.

159. Zhang Y, Gu X, Li D, Cai L and Xu Q: METTL3 regulates osteoblast differentiation and inflammatory response via Smad signaling and MAPK Signaling. Int J Mol Sci 21: 199, 2019.

160. Yu R, Li Q, Feng Z, Cai L and Xu Q: m6A reader YTHDF2 regulates LPS-induced inflammatory response. Int J Mol Sci 20 $1323,2019$.

161. Wang T and He C: TNF- $\alpha$ and IL-6: The link between immune and bone system. Curr Drug Targets 20: 213-227, 2020.

162. Mathew AJ and Ravindran V: Infections and arthritis. Best Pract Res Clin Rheumatol 28: 935-959, 2014.

163. Harth M and Nielson WR: Pain and affective distress in arthritis: Relationship to immunity and inflammation. Expert Rev Clin Immunol 15: 541-552, 2019.

164. Parkinson L, Waters DL and Franck L: Systematic review of the impact of osteoarthritis on health outcomes for comorbid disease in older people. Osteoarthritis Cartilage 25: 1751-1770, 2017.

165. Glyn-Jones S, Palmer AJ, Agricola R, Price AJ, Vincent TL, Weinans H and Carr AJ: Osteoarthritis. Lancet 386: 376-387, 2015

166. Abramoff B and Caldera FE: Osteoarthritis: Pathology, diagnosis, and treatment options. Med Clin North Am 104: 293-311, 2020

167. Liossis SN and Tsokos GC: Cellular immunity in osteoarthritis: Novel concepts for an old disease. Clin Diagn Lab Immunol 5 : 427-429, 1998.

168. Sakata M, Tsuruha JI, Masuko-Hongo K, Nakamura H, Matsui T, Sudo A, Nishioka K and Kato T: Autoantibodies to osteopontin in patients with osteoarthritis and rheumatoid arthritis. J Rheumatol 28: 1492-1495, 2001.

169. Walker J, Gordon T, Lester S, Downie-Doyle S, McEvoy D, Pile K, Waterman S and Rischmueller M: Increased severity of lower urinary tract symptoms and daytime somnolence in primary Sjogren's syndrome. J Rheumatol 30: 2406-2412, 2003.

170. Kato T, Xiang Y, Nakamura $\mathrm{H}$ and Nishioka K: Neoantigens in osteoarthritic cartilage. Curr Opin Rheumatol 16: 604-608, 2004

171. Zhao W, Wang T, Luo Q, Chen Y, Leung VY, Wen C, Shah MF, Pan H, Chiu K, Cao X and Lu WW: Cartilage degeneration and excessive subchondral bone formation in spontaneous osteoarthritis involves altered TGF- $\beta$ signaling. J Orthop Res 34 763-770, 2016

172. Liu Q, Li M, Jiang L, Jiang R and Fu B: METTL3 promotes experimental osteoarthritis development by regulating inflammatory response and apoptosis in chondrocyte. Biochem Biophys Res Commun 516: 22-27, 2019.

173. Goldring SR and Goldring MB: The role of cytokines in cartilage matrix degeneration in osteoarthritis. Clin Orthop Relat Res (427 Suppl): S27-S36, 2004.

174. Yang F, Zhou S, Wang C, Huang Y, Li H, Wang Y, Zhu Z, Tang $\mathrm{J}$ and Yan M: Epigenetic modifications of interleukin- 6 in synovial fibroblasts from osteoarthritis patients. Sci Rep 7: 43592, 2017.

175. Guo Q, Wang Y, Xu D, Nossent J, Pavlos NJ and Xu J: Rheumatoid arthritis: Pathological mechanisms and modern pharmacologic therapies. Bone Res 6: 15, 2018.

176. Li HB, Tong J, Zhu S, Batista PJ, Duffy EE, Zhao J, Bailis W, Cao G, Kroehling L, Chen Y, et al: $\mathrm{m}^{6} \mathrm{~A}$ mRNA methylation controls $\mathrm{T}$ cell homeostasis by targeting the IL-7/STAT5/SOCS pathways. Nature 548: 338-342, 2017.

177. Wang J, Yan S, Lu H, Wang S and Xu D: METTL3 attenuates LPS-induced inflammatory response in macrophages via NF- $\kappa$ B signaling pathway. Mediators Inflamm 2019: 3120391, 2019

178. Mo XB, Zhang YH and Lei SF: Genome-wide identification of $\mathrm{N}^{6}$-methyladenosine $\left(\mathrm{m}^{6} \mathrm{~A}\right)$ SNPs associated with rheumatoid arthritis. Front Genet 9: 299, 2018.
179. Zheng Y, Nie P, Peng D, He Z, Liu M, Xie Y, Miao Y, Zuo Z and Ren J: m6AVar: A database of functional variants involved in m6A modification. Nucleic Acids Res 46: D139-D145, 2018.

180. Smolen JS, Aletaha D, Barton A, Burmester GR, Emery P, Firestein GS, Kavanaugh A, McInnes IB, Solomon DH, Strand V and Yamamoto K: Rheumatoid arthritis. Nat Rev Dis Primers 4 $18001,2018$.

181. Kondo Y, Yokosawa M, Kaneko S, Furuyama K, Segawa S, Tsuboi H, Matsumoto I and Sumida T: Review: Transcriptional regulation of $\mathrm{CD} 4+\mathrm{T}$ cell differentiation in experimentally induced arthritis and rheumatoid arthritis. Arthritis Rheumatol 70: 653-661, 2018

182. Noack M and Miossec P: Th17 and regulatory T cell balance in autoimmune and inflammatory diseases. Autoimmun Rev 13: 668-677, 2014

183. Hunt L, Hensor EM, Nam J, Burska AN, Parmar R, Emery P and Ponchel F: T cell subsets: An immunological biomarker to predict progression to clinical arthritis in ACPA-positive individuals. Ann Rheum Dis 75: 1884-1889, 2016.

184. Kumar BV, Connors TJ and Farber DL: Human T cell development, localization, and function throughout life. Immunity 48: 202-213, 2018.

185. Abada A and Elazar Z: Getting ready for building: Signaling and autophagosome biogenesis. Embo Rep 15: 839-852, 2014.

186. Wang DW, Wu LW, Cao Y, Yang L, Liu W, E XQ, Ji G and Bi ZG: A novel mechanism of mTORC1-mediated serine/glycine metabolism in osteosarcoma development. Cell Signal 29: 107-114, 2017.

187. Miao W, Chen J, Jia L, Ma J and Song D: The m6A methyltransferase METTL3 promotes osteosarcoma progression by regulating the m6A level of LEF1. Biochem Biophys Res Commun 516: 719-725, 2019

188. Nguyen DX, Chiang AC, Zhang XH, Kim JY, Kris MG Ladanyi M, Gerald WL and Massagué J: WNT/TCF signaling through LEF1 and HOXB9 mediates lung adenocarcinoma metastasis. Cell 138: 51-62, 2009.

189. Jia P, Wei G, Zhou C, Gao Q, Wu Y, Sun X and Li X: Upregulation of miR-212 inhibits migration and tumorigenicity and inactivates Wnt/ $\beta$-catenin signaling in human hepatocellular carcinoma. Technol Cancer Res Treat 17: 1533034618765221, 2018

190. Wu L, Zhao JC, Kim J, Jin HJ, Wang CY and Yu J: ERG is a critical regulator of $\mathrm{Wnt} / \mathrm{LEF} 1$ signaling in prostate cancer. Cancer Res 73: 6068-6079, 2013.

191. Ling Z, Chen L and Zhao J: m6A-dependent up-regulation of DRG1 by METTL3 and ELAVL1 promotes growth, migration, and colony formation in osteosarcoma. Biosci Rep 40: BSR20200282, 2020.

192. Coker H, Wei G and Brockdorff N: m6A modification of non-coding RNA and the control of mammalian gene expression. Biochim Biophys Acta Gene Regul Mech 1862: 310-318, 2019.

193. Li J, Rao B, Yang J, Liu L, Huang M, Liu X, Cui G, Li C, Han Q, Yang H, et al: Dysregulated m6A-related regulators are associated with tumor metastasis and poor prognosis in osteosarcoma. Front Oncol 10: 769, 2020

194. Fan D, Xia Y, Lu C, Ye Q, Xi X, Wang Q, Wang Z, Wang C and Xiao C: Regulatory role of the RNA N ${ }^{6}$-methyladenosine modification in immunoregulatory cells and immune-related bone homeostasis associated with rheumatoid arthritis. Front Cell Dev Biol 8: 627893, 2020

195. Liu T, Wei Q, Jin J, Luo Q, Liu Y, Yang Y, Cheng C, Li L, Pi J, Si Y, et al: The m6A reader YTHDF1 promotes ovarian cancer progression via augmenting EIF3C translation. Nucleic Acids Res 48: 3816-3831, 2020.

196. Ma Z and Ji J: N6-methyladenosine (m6A) RNA modification in cancer stem cells. Stem Cells: Sep 27, 2020 (Epub Ahead of Print).

197. Patil DP, Pickering BF and Jaffrey SR: Reading $\mathrm{m}^{6} \mathrm{~A}$ in the transcriptome: $\mathrm{m}^{6} \mathrm{~A}$-binding proteins. Trends Cell Biol 28: 113-127, 2018.

198. Dai DJ, Wang HY, Zhu LY, Jin HC and Wang X: $\mathrm{N}^{6}$-methyladenosine links RNA metabolism to cancer progression. Cell Death Dis 9: 124, 2018.

199. Wang HF, Kuang MJ, Han SJ, Wang AB, Qiu J, Wang F, Tan BY and Wang DC: BMP2 modified by the $\mathrm{m}^{6} \mathrm{~A}$ demethylation enzyme ALKBH5 in the ossification of the ligamentum flavum through the AKT signaling pathway. Calcified Tissue Int 106 486-493, 2020

200.Zhang W, He L, Liu Z, Ren X, Qi L, Wan L, Wang W, Tu C and Li Z: Multifaceted functions and novel insight into the regulatory role of RNA $\mathrm{N}^{6}$-methyladenosine modification in musculoskeletal disorders. Front Cell Dev Biol 8: 870, 2020. 